\title{
Consistent response of Indian summer monsoon to Middle East dust in observations and simulations
}

\author{
Q. Jin ${ }^{1}$, J. Wei ${ }^{1}$, Z.-L. Yang ${ }^{1}$, B. Pu ${ }^{1}$, and J. Huang ${ }^{2}$ \\ ${ }^{1}$ Department of Geological Sciences, University of Texas at Austin, 1 University Station C1100, Austin, Texas 78712, USA \\ ${ }^{2}$ Key Laboratory for Semi-Arid Climate Change of the Ministry of Education, College of Atmospheric Sciences, Lanzhou \\ University, Lanzhou, Gansu 730000, China
}

Correspondence to: Z.-L. Yang (liang@jsg.utexas.edu)

Received: 31 March 2015 - Published in Atmos. Chem. Phys. Discuss.: 11 June 2015

Revised: 7 August 2015 - Accepted: 25 August 2015 - Published: 2 September 2015

\begin{abstract}
The response of the Indian summer monsoon (ISM) circulation and precipitation to Middle East dust aerosols on sub-seasonal timescales is studied using observations and the Weather Research and Forecasting model coupled with online chemistry (WRF-Chem). Satellite data show that the ISM rainfall in coastal southwest India, central and northern India, and Pakistan is closely associated with the Middle East dust aerosols. The physical mechanism behind this dust-ISM rainfall connection is examined through ensemble simulations with and without dust emissions. Each ensemble includes 16 members with various physical and chemical schemes to consider the model uncertainties in parameterizing short-wave radiation, the planetary boundary layer, and aerosol chemical mixing rules. Experiments show that dust aerosols increase rainfall by about $0.44 \mathrm{~mm}_{\text {day }}{ }^{-1}$ ( $\sim 10 \%$ of the climatology) in coastal southwest India, central and northern India, and north Pakistan, a pattern consistent with the observed relationship. The ensemble mean rainfall response over India shows a much stronger spatial correlation with the observed rainfall response than any other ensemble members. The largest modeling uncertainties are from the boundary layer schemes, followed by short-wave radiation schemes. In WRF-Chem, the dust aerosol optical depth (AOD) over the Middle East shows the strongest correlation with the ISM rainfall response when dust AOD leads rainfall response by about 11 days. Further analyses show that increased ISM rainfall is related to enhanced southwesterly monsoon flow and moisture transport from the Arabian Sea to the Indian subcontinent, which are associated with the development of an anomalous low-pressure system over the Arabian Sea, the southern Arabian Peninsula, and the Ira-
\end{abstract}

nian Plateau due to dust-induced heating in the troposphere. The dust-induced heating in the mid-upper troposphere is mainly located in the Iranian Plateau rather than the Tibetan Plateau. This study demonstrates a thermodynamic mechanism that links remote desert dust emissions in the Middle East to ISM circulation and precipitation variability on subseasonal timescales, which may have implications for ISM rainfall forecasts.

\section{Introduction}

Aerosols, from both natural sources (e.g., mineral dust, sea salt, and volcanic eruptions) and anthropogenic emissions (e.g., black carbon and sulfate), can influence climate by scattering and absorbing solar and terrestrial radiation (the direct effect) and by serving as cloud condensation nuclei and ice nuclei and altering cloud microphysical properties (the indirect effect). The Indian summer monsoon (ISM) region and its surrounding areas have been identified as having high aerosol concentrations (e.g., Kuhlmann and Quaas, 2010) and this large aerosol loading has been increasing dramatically during the past decade due to population growth and more frequent dust activity (Hsu et al., 2012). The potential impacts of aerosols on ISM is an important issue because about one-third of the world's population rely heavily on the ISM rainfall for water supply and agricultural production.

Both observational and modeling studies suggest that local anthropogenic aerosols, especially black carbon over northern India, have major impacts on ISM through the "solar dimming effect" and the "elevated heat pump" (EHP) ef- 
fect on different timescales (Ramanathan et al., 2005; Lau et al., 2006; Wang et al., 2009b; Kuhlmann and Quaas, 2010; Nigam and Bollasina, 2010; Bollasina et al., 2011; Lau and Kim, 2011; Bollasina et al., 2013). The "solar dimming effect" proposes that the anthropogenic aerosol-induced reduction of north-south land-sea thermal contrast through aerosols' surface cooling effect contributes to a weaker meridional monsoon circulation. In contrast, the EHP effect hypothesizes that the anthropogenic and desert dust aerosols stacked up on the southern slope of the Tibetan Plateau can heat the air in the mid-to-upper troposphere due to their high elevation, which in turn results in the earlier onset of the Indian summer monsoon and more precipitation during monsoon season. In addition to local anthropogenic aerosols, remote mineral dust aerosols, which dominate the aerosol concentrations in the Middle East and the Arabian Sea (AS), can play an important role in altering the ISM rainfall. Wang et al. (2009a) found that dust aerosols can absorb solar radiation in a way similar to black carbon in the ISM and nearby regions. Using CALIPSO satellite retrievals, Kuhlmann and Quaas (2010) examined the aerosol constituents and concluded that the AS has heavy dust loading, with up to $80 \%$ of measurements identified as either dust or polluted dust during the Asian summer monsoon season. Jin et al. (2014; hereafter J2014) found that dust aerosols contribute $53 \%$ of the total aerosol optical depth (AOD) over the AS and the Iranian Plateau (IP) during the ISM season based on aerosol reanalysis.

The above studies have documented spatiotemporal features of mineral dust in the Middle East and the ISM surrounding regions, but have not focused on the impacts of remote Middle East dust on the ISM system. Until recently, general circulation model (GCM) experiments and observational analyses have demonstrated significant impacts of remote Middle East dust aerosols on the ISM rainfall. Vinoj et al. (2014; hereafter V2014) found a positive relationship between the ISM rainfall in southern India and dust aerosols over the AS, west Asia and the Arabian Peninsula (AP) using a GCM. They proposed that dust-induced convergence over eastern North Africa and the AP by heating the atmosphere increases moisture transfer over India, which in turn modulates monsoon rainfall over south India within a week. Based on satellite-retrieved AOD and rainfall and meteorological reanalysis, J2014 proposed an AOD-ISM rainfall hypothesis based on a dust-induced EHP effect centered over the IP and extending southward to the AS. By connecting the dust and ISM, this hypothesis explains the observed positive correlation between Middle East dust aerosols and ISM rainfall. Although V2014 and J2014 proposed a similar physical mechanism for the AOD-ISM rainfall correlation, the spatial patterns of increased ISM rainfall from their studies are quite different. In V2014, the rainfall response was found only in southern and central India and mainly located in south India, with only a minor increase or even decrease in rainfall in central India. However, in J2014, increased rainfall was observed in Pakistan and all of India except for southeast India; the largest increase in rainfall was located in the IndoGangetic Plain (IGP) region. In addition, V2014 stated no cross-correlation between AOD and ISM rainfall within a week in observations, but J2014 found a significant crosscorrelation, with its maximum occurring when AOD leads the ISM rainfall response by 13 days. Most recently, Solmon et al. (2015; hereafter S2015) studied the interaction between Middle East dust and ISM rainfall on interannual to decadal timescales using a regional climate model (RCM). They found that the dust aerosols could increase rainfall in southern India, while it decreased rainfall in central and northern India (CNI) and Pakistan during the period of 2000 to 2009. All three studies have focused on the dynamic impact of dust radiative forcing on the ISM rainfall, but their results differ or have opposite signs in terms of spatial distributions of the rainfall response in central and north India and Pakistan.

Our study uses observations and model experiments to understand the discrepancies among the above studies. We have three research questions. First, in what areas is rainfall sensitive to Middle East dust aerosols? The AOD-ISM rainfall relationship based on observations can provide a baseline for model evaluations. Secondly, how are the observed AOD-ISM interactions represented in the Weather Research and Forecasting model (Skamarock et al., 2008) coupled with online chemistry (WRF-Chem) (Grell et al., 2005), and how do the modeling uncertainties affect our conclusions? In V2014, 19 ensemble simulations were conducted during a short period (10 days). In S2015, three ensemble simulations were created by perturbing the boundary conditions. In our study, 16 pairs of ensemble simulations are conducted using a perturbed physics and chemistry ensemble (PPCE) method during the boreal summer 2008, a period with strong dust emissions. We believe that by using PPCE members, we can better capture the uncertainties in the monsoon response to dust because the AOD-ISM rainfall hypothesis is based on both chemical properties (e.g., aerosol chemical mixing rules) of dust and their impact on atmospheric physical processes (e.g., radiation and circulations) (McFiggans et al., 2006). The dust-induced impact is then examined by the ensemble mean differences. Finally, is the 13-day maximum cross-correlation found in observations in J2014 captured by WRF-Chem? This question is critical because if the AODISM rainfall hypothesis is true, AOD must lead the ISM rainfall response in the model.

\section{Model and experiment}

\subsection{Model}

WRF-Chem simultaneously simulates the evolution of trace gases and aerosols and their interactions with meteorological fields. It incorporates the second-generation Regional Acid 
Deposition Model (RADM2) gas-phase chemical mechanism (Stockwell et al., 1997) and the Modal Aerosol Dynamics model for Europe (MADE) primary aerosol scheme (Schell et al., 2001) coupling the Secondary Organic Aerosol Model (SORGAM) aerosol scheme for simulating secondary organic aerosol formation from biogenic and anthropogenic emissions (Ackermann et al., 1998). RADM2 uses a simplified lumped molecular approach with surrogate species that classifies species based on similarity in oxidation reactivity and emissions magnitudes (Middleton et al., 1990) to represent atmospheric chemical compositions. RADM2 resolves 63 gas phase species, including 21 inorganic and 42 organic species. It also includes 21 photolysis and 124 thermal reactions to simulate the primary gas-phase chemical reactions.

The major aerosol species treated in the MADESORGAM aerosol scheme include sulfate, nitrite, ammonium, soil-derived dust, organic carbon (OC), black carbon (BC), sea salt, and water. Three overlapping modal modes are used to represent aerosol size distribution in MADE-SORGAM: Aitken $(0.01-0.1 \mu \mathrm{m})$, accumulation $(0.1-1.0 \mu \mathrm{m})$, and coarse modes $(1.0-10.0 \mu \mathrm{m})$, assuming a log-normal distribution within each mode (Liu et al., 2012; Albani et al., 2014; Mahowald et al., 2014). Sea salt, soilderived dust, and anthropogenic emissions are treated in the accumulation and coarse modes, and other aerosol species are treated in the Aitken and accumulation modes. Aerosols are assumed to be internally mixed within each mode so that all particles have the same chemical composition and are externally mixed between modes.

Aerosol dynamics implemented in the MADE-SORGAM aerosol scheme include particle formation, condensational growth, coagulation, and deposition. Particles are formed by direct particle emissions and secondary formation of nucleation. Direct emissions includes biomass burning, anthropogenic emissions, soil-derived dust, sea salt, and so on. Nucleation dynamics is incorporated to consider the formation of secondary aerosols in sulfuric acid-water conditions (Kulmala et al., 1998). The growth of aerosol particle size by vapor condensation is calculated based on the rate of change of the third moment of aerosol size log-normal distribution while neglecting the Kelvin effect (Binkowski and Shankar, 1995). Because aerosol particle size is defined as dry particle radius, the condensation does not cause particle shift between modes. Coagulation caused by Brownian motion is considered in MADE. The collision of particles within one mode can form a new particle in that mode; the collision of particles from two different modes can form a new particle in the mode with larger diameter (Whitby and McMurry, 1997). Dry deposition of trace gases is calculated using dry deposition velocity, which is parameterized by an aerodynamic sub-layer and surface resistance. Dry deposition of aerosols is calculated using gravitational sedimentation velocity (Wesely, 1989), resistance due to interception (Ruijgrok et al., 1995; Zhang et al., 2001), impaction (Peters and Eiden, 1992), and Brownian motion (Binkowski and
Shankar, 1995). Wet deposition of both aerosols and trace gases in-cloud and below-cloud are also treated in the model. Cloud-borne aerosols and cloud water-dissolved trace gases are assumed to be removed immediately from the atmosphere by collection of rainfall, ice, snow, and graupel. The removal rate of cloud-borne aerosols and trace gases is approximately identical to the removal rate of cloud water by precipitation, which is calculated by a microphysics scheme in the model (e.g., Lin microphysics scheme). Below-cloud scavenging of aerosols and trace gases by precipitation are also treated following Easter et al. (2004).

Each aerosol species is assigned a complex refractive index, with its real part indicating phase velocity of scattering and its imaginary part indicating absorption when solar radiation propagates through the atmosphere. In the released version of WRF-Chem, mineral dust aerosols are assigned the wavelength-independent refractive index $(1.550+i 0.003)$ within the short-wave (SW) range. However, the absorbing ability of dust aerosols decreases as wavelength increases (Wagner et al., 2012; Utry et al., 2015). Therefore, in this study, wavelength-dependent refractive indices are employed from the Rapid Radiative Transfer Model GCM application (RRTMG) SW radiation scheme (Iacono et al., 2008) in the Community Atmosphere Model. The imaginary parts of the refractive indices are $0.024,0.0135,0.0063$, and 0.004 for wavelengths at $300,400,600$, and $999 \mathrm{~nm}$, respectively. The real part of dust refractive index is the same as in the released version of WRF-Chem. Aerosol optical properties such as optical depth, single scattering albedo, asymmetry factor, extinction, and backscatter coefficient are calculated in three dimensions at the abovementioned four SW wavelengths using Mie theory. For long-wave radiation, aerosol optical depth and extinction coefficient are calculated at 16 wavelengths (3.4-55.6 $\mu \mathrm{m})$.

\subsection{Emissions}

\subsubsection{Dust emissions}

The Goddard Chemistry Aerosol Radiation and Transport (GOCART) dust emissions scheme (Ginoux et al., 2001) coupled with the MADE-SORGAM aerosol scheme is used to simulate dust emissions. In GOCART, dust emissions are calculated based on wind speed and an erodibility map (Prospero et al., 2002; Zender et al., 2003b) as

$G=C S_{p} u_{10 \mathrm{~m}}^{2}\left(u_{10 \mathrm{~m}}-u_{\mathrm{t}}\right)$,

where $G$ is the dust emissions flux $\left(\mu \mathrm{g} \mathrm{m}^{-2} \mathrm{~s}^{-1}\right), C$ is a dimensionless empirical proportionality constant, $S$ is the soil erodibility of potential dust source regions (Fig. 1b), $s_{p}$ is a fraction of mass of each size bin of dust emissions, $u_{10 \mathrm{~m}}^{2}$ is wind speed at $10 \mathrm{~m}$ above the surface, and $u_{\mathrm{t}}$ is the wind speed threshold under which dust emissions do not occur. GOCART represents dust emissions in five bins, with averaged radii of $0.73,1.40,2.40,4.50$, and $8.00 \mu \mathrm{m}$. The com- 

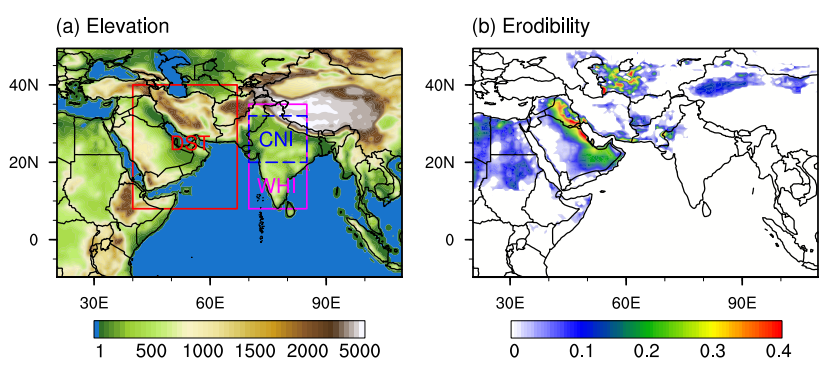

Figure 1. (a) Elevation map in WRF-Chem domain (unit: $m$ ). "DST", "WHI", and "CNI" represent the remote dust region $\left(8^{\circ}-\right.$ $\left.40^{\circ} \mathrm{N}, 40^{\circ}-67^{\circ} \mathrm{E}\right)$, the entire India $\left(8^{\circ}-35^{\circ} \mathrm{N}, 70^{\circ}-85^{\circ} \mathrm{E}\right)$, and central and northern India $\left(20^{\circ}-32^{\circ} \mathrm{N}, 70^{\circ}-85^{\circ} \mathrm{E}\right)$, respectively. (b) Soil erodibility (unitless) map used in WRF-Chem dust emissions scheme.

puted dust emissions are aggregated accordingly into the accumulation and coarse modal modes for MADE-SORGAM to match the representation of particle size distribution in the aerosol scheme.

\subsubsection{Other emissions}

The anthropogenic emissions for WRF-Chem come from the mixture of the Reanalysis of the Tropospheric chemical composition emissions inventory (https://verc.enes.org/), Emission Database for Global Atmospheric Research (http: //www.mnp.nl/edgar/introduction), and GOCART. These anthropogenic emissions include 20 gases and 3 aerosol species, including BC, OC, and sulfate. Background emissions are from the GOCART data set, including nitrate, $\mathrm{H}_{2} \mathrm{O}_{2}$, hydroxyl radical, and dimethyl sulfide. Biogenic emissions are calculated online using the Model of Emissions of Gases and Aerosols from Nature (Guenther et al., 2012). Biomass burning emissions are obtained from the Global Fire Emissions Database version 2 with an 8-day temporal resolution (http://www.globalfiredata.org/index.html).

\subsection{Experiment design}

In this study, WRF-Chem 3.5 is configured over the Middle East and the ISM region $\left(-9.68^{\circ} \mathrm{S}-49.60^{\circ} \mathrm{N}, 20.41^{\circ}-\right.$ $109.87^{\circ}$ E, see Fig. 1a) with $160 \times 120$ grid points centered over the AS $\left(23^{\circ} \mathrm{E}, 65^{\circ} \mathrm{N}\right)$, at a $54 \mathrm{~km}$ horizontal resolution and 30 vertical layers up to $50 \mathrm{hPa}$. This domain covers major dust source regions represented by erodibility in the model, as shown in Fig. 1b. A few key areas are selected to examine the relationship between Middle East dust and the ISM rainfall. The dust (DST) box is chosen to include the heavy dustloading areas, i.e., the AS, the AP, the IP, Afghanistan, and Turkmenistan. The whole India (WHI) box and CNI boxes are chosen to represent the rainfall over the whole India and central and northern Indian, respectively.

All simulations cover a 104-day period from 20 May 2008 to 31 August 2008 without nudging. The first 12 days for each integration are discarded as "spin up" to reduce the impact of initial conditions, and the analysis focuses on the monsoon season from 1 June 2008 to 31 August 2008. Meteorological fields from the European Centre for Medium-Range Weather Forecasts (ECMWF) Interim Reanalysis (ERA-I) global reanalysis data are prescribed as lateral and lower boundary conditions (e.g., sea surface temperature, SST) and initial conditions.

WRF-Chem provides multiple options for physical and chemical parameterizations. For physical parameterizations, we used the Noah land surface model (Chen et al., 2001), the RRTMG SW and long-wave (LW) radiation schemes, the Yonsei University (YSU) planetary boundary layer (PBL) scheme (Hong et al., 2006), and Lin's double-moment microphysical scheme (Lin et al., 1983). An updated version of the Grell-Devenyi (Grell and Devenyi, 2002) cumulus parameterization scheme is used, which includes feedback from the parameterized convection to the atmospheric RRTMG radiation scheme and the Fast-J photolysis scheme. For the chemical parameterizations, we used RADM2 gas-phase chemistry, MOSAIC-SORGAM aerosol chemistry with aqueous reactions, and the Fast-J photolysis scheme. Table 1 summarizes the model schemes used in this study.

To understand how the model uncertainties and errors affect our results, additional alternative physical and chemical parameterization schemes are used to create ensemble simulations. V2014 and S2015 created ensemble members by perturbing initial and boundary conditions, respectively. In this study, two groups of simulations were designed based on the presence and absence of dust emissions. The reference group considers all aerosol forcing (including mineral dust, sea salt, biomass burning, biogenic emissions, and anthropogenic emissions; ALLF) and the perturbed group is identical to the reference group but without dust emissions (NDST). Within each group, 16 ensemble members were created using the PPCE method because we are more interested in how differences in the aerosol chemical mixing rules, aerosol diffusion in the atmospheric boundary layer, and radiation schemes may affect the simulations of the ISM rainfall and variability.

Four different aerosol chemical mixing rules are used to calculate the aerosol optical properties: volume approximation, Maxwell-Garnett approximation, exact volume, and exact Maxwell-Garnett schemes (Fast et al., 2006; Barnard et al., 2010). The volume approximation assumption calculates refractive indices based on the volume average of each aerosol species. The Maxwell-Garnett method assumes a random distribution of black carbon in spherical particles. Both of the volume and Maxwell-Garnett schemes call for the full Mie calculation only at the first time step (Ghan et al., 2001). However, the exact volume and exact MaxwellGarnett schemes call for the full Mie calculation at each time step.

Two SW radiation schemes - RRTMG and Goddard, and two PBL schemes - YSU and Bougeault-Lacarrère 
Table 1. Configuration options of WRF-Chem used in this study.

\begin{tabular}{lll}
\hline \multicolumn{2}{c}{ Atmospheric process } & Model option \\
\hline \multirow{7}{*}{ Physics } & Long-wave radiation & RRTMG \\
& Short-wave radiation & RRTMG/Goddard \\
& Surface layer & Monin-Obukhov \\
& Land surface & Noah \\
& Boundary layer & YSU/BouLac \\
& Cumulus clouds & Grell-Freitas \\
& Cloud microphysics & Lin et al. \\
\hline Chemistry & Gas-phase chemistry & RADM2 \\
& Aerosol chemistry & MADE-SORGAM with aqueous reactions \\
& Photolysis & Fast-J \\
\hline Emission & Dust emissions & GOCART \\
& Sea salt emissions & MADE-SORGAM \\
& Anthropogenic emissions & Reanalysis of the Tropospheric and Emission Database for Global Atmospheric Research \\
& Biogenic emissions & The Model of Emissions of Gases and Aerosols from Nature version 2 \\
& Fire emissions & MODIS \\
\hline
\end{tabular}

(BouLac) are employed. The sub-grid cloud parameterization in RRTMG can simulate interactions between aerosol radiative forcing and sub-grid clouds. YSU and BouLac represent two types of PBL schemes - turbulent kinetic energy and first-order closure schemes (Shin and Hong, 2011), respectively. In total, there are 32 ensemble members, which are comprised of $2 \mathrm{PBL} \times 2 \mathrm{SW} \times 4$ composition $\times 2$ options with and without dust emissions as detailed in Table 2. Note that the LW radiation-induced uncertainties are not considered in this study, because only the RRTMG LW radiation scheme is coupled with the aerosol scheme.

\section{Data sets}

\subsection{AOD}

The Moderate-resolution Imaging Spectroradiometer (MODIS) instrument aboard the National Aeronautics and Space Administration (NASA) Terra and Aqua platforms is uniquely designed to observe and monitor atmospheric trace gases, clouds, and tropospheric aerosols. MODIS provides two kinds of AOD data, "dark target" and "deep-blue" daily and monthly AOD at the wavelength of $550 \mathrm{~nm}$ with resolution of $1^{\circ} \times 1^{\circ}$ from 1 March 2000 to the present (http://modis-atmos.gsfc.nasa.gov/). The "dark target" algorithm provides best results over the oceans and on land with low surface albedo; the "deep-blue" algorithm retrieves AOD over regions with bright surfaces, such as desert (Hsu et al., 2004). In our study, both kinds of AOD are combined to expand the spatial coverage by simply assigning the "deep-blue" AOD to the grid if the "dark target" AOD is missed. In this way, the global AOD is available over both oceans and land. Because of a broad swath of $2330 \mathrm{~km}$, MODIS images the entire earth every 1-2 days.
The Multi-angle Imaging Spectroradiometer (MISR) instrument provides detailed aerosol properties on the global scale. MISR onboard Terra, NASA's first Earth Observing System spacecraft, is designed to improve our understanding of the regional and global impacts of different types of atmospheric particles and clouds on climate (Diner et al., 1998). With nine cameras, MISR views Earth in nine different directions, and each piece of Earth's surface below is successively imaged by all nine cameras, at each of the four wavelengths (blue, green, red, and near infrared). This specific feature of MISR can help estimate aerosol particle size and composition with unprecedented accuracy. Based on the particle size information, the aerosol's effects on climate caused by natural sources and human activities can be isolated. The swath for MISR is only $360 \mathrm{~km}$, which gives MISR a longer global span time of 9 days.

The ECMWF Monitoring Atmospheric Composition and Climate $(\mathrm{MACC})\left(0.5^{\circ} \times 0.5^{\circ}\right)$ aerosol reanalysis data provide partial AOD of various aerosol types (Benedetti et al., 2009). MACC assimilates MODIS dark target production collection 5, which does not include AOD retrievals over the bright surface using the "deep-blue" algorithm.

\subsection{Precipitation}

Four precipitation data sets are used. The Tropical Rainfall Measuring Mission $(\mathrm{TRMM})\left(0.25^{\circ} \times 0.25^{\circ}\right)$ monthly 3B43 (version 7) and daily 3B42 (version 7) precipitation data sets are employed (Huffman et al., 2007). These two products combine multiple independent satellite precipitation estimates and Global Precipitation Climatology Centre rain gauge analysis. The Global Precipitation Climatology Project (GPCP) $\left(1^{\circ} \times 1^{\circ}\right)$ monthly and daily (version 2$)$ rainfall data sets are produced by combining multiple satellite- 
Table 2. Various schemes employed to create the ensemble members.

\begin{tabular}{|c|c|c|c|}
\hline Scheme & Option & & Description \\
\hline \multirow[t]{2}{*}{$\begin{array}{l}\text { Short-wave } \\
\text { radiation }\end{array}$} & sw4 & Goddard & $\begin{array}{l}\text { 1. } 11 \text { spectral bands ( } 7 \mathrm{UV}, 1 \text { PAR, } 3 \text { infrared) } \\
\text { 2. a two-stream adding algorithm } \\
\text { 3. no interactions with sub-grid clouds }\end{array}$ \\
\hline & sw2 & RRTMG & $\begin{array}{l}\text { 1. } 14 \text { spectral bands ( } 3 \mathrm{UV}, 2 \text { PAR, } 9 \text { infrared) } \\
\text { 2. a two-stream algorithm for multiple scattering } \\
\text { 3. represents sub-grid cloud variability by McICA with } \\
\text { maximum-random cloud overlap }\end{array}$ \\
\hline \multirow[t]{2}{*}{$\begin{array}{l}\text { Planetary } \\
\text { boundary } \\
\text { layer }\end{array}$} & $\mathrm{pb} 1$ & YSU & $\begin{array}{l}\text { 1. first-order closure } \\
\text { 2. } K \text { profile and non-local mixing } \\
\text { 3. explicit treatment of entrainment }\end{array}$ \\
\hline & $\mathrm{pb} 8$ & BouLac & $\begin{array}{l}\text { 1. one-and-a-half order closure } \\
\text { 2. prognostic turbulent kinetic energy equation }\end{array}$ \\
\hline \multirow[t]{4}{*}{$\begin{array}{l}\text { Aerosol chemical } \\
\text { mixing rules }\end{array}$} & op1 & volume & $\begin{array}{l}\text { 1. internal-mixing of aerosol composition } \\
\text { 2. full Mie calculations are called for only at the first time step }\end{array}$ \\
\hline & op2 & Maxwell & $\begin{array}{l}\text { 1. randomly distributes black carbon within a particle } \\
\text { 2. full Mie calculations are called for only at the first time step }\end{array}$ \\
\hline & op3 & $\begin{array}{l}\text { exact } \\
\text { volume }\end{array}$ & same as volume, but use full Mie calculation at each time step \\
\hline & op4 & $\begin{array}{l}\text { exact } \\
\text { Maxwell }\end{array}$ & same as Maxwell, but use full Mie calculation at each time step \\
\hline
\end{tabular}

UV, PAR, and McICA stand for ultraviolet, photosynthetically active radiation, and the Monte Carlo Independent Column Approximation, respectively.

retrieved precipitation and surface precipitation gauge analyses (Huffman et al., 2001). The Climate Prediction Center Merged Analysis of Precipitation (CMAP) $\left(2.5^{\circ} \times 2.5^{\circ}\right)$ monthly and pentad rainfall data sets are produced based on five kinds of satellite retrievals (Xie and Arkin, 1997). The National Oceanic and Atmospheric Administration PRECipitation REConstruction over land $(\mathrm{PREC} / \mathrm{L})\left(0.5^{\circ} \times 0.5^{\circ}\right)$ monthly rainfall data sets are constructed by precipitation gauge observations (Chen et al., 2002).

\subsection{Reanalysis}

ERA-I $\left(0.5^{\circ} \times 0.5^{\circ}\right)$ (Dee et al., 2011) is adopted to provide WRF-Chem with lateral and lower boundary conditions, as well as initial conditions. The Modern EraRetrospective Analysis for Research and Applications (MERRA) $\left(1 / 2^{\circ} \times 2 / 3^{\circ}\right)$ (Rienecker et al., 2011) is also used for comparison with ERA-I and model evaluation in terms of geopotential height (GPH) and circulations.

\section{Evaluation of ISM and AOD simulated by WRF-Chem}

Figure 2a-c illustrate the spatial patterns of the observed and modeled rainfall averaged for June-July-August (JJA)
2008. During the ISM season, TRMM and GPCP observed heavy rainfall in coastal southwest India (CSWI) and CNI. The WRF-Chem ensemble mean rainfall in 16 ALLF members (Fig. 2c) shows a spatial pattern quite consistent with that of TRMM and GPCP. Note that the model overestimates rainfall in CSWI and underestimates rainfall in CNI. Similar rainfall differences between model simulations and observations were also found in both RCM (e.g., Solmon et al., 2015) and GCM (e.g., Levine and Turner, 2012) studies. The underestimated rainfall in CNI can be partly attributed to the lack of representation of agricultural irrigation in the model. Intensive irrigation activities occurring during JJA over the IGP can increase local evapotranspiration, and thus increase rainfall (Douglas et al., 2009; Guimberteau et al., 2012). Figure $2 \mathrm{~d}-\mathrm{f}$ show the GPH and circulation at $850 \mathrm{hPa}$ from reanalysis and WRF-Chem. The ISM system is featured by strong cross-equator southerly winds in the tropical Indian Ocean and southwesterly winds in the lower troposphere in the AS and the Bay of Bengal. Another ISM feature is the deeper low-pressure centered over north India and the IP. In general, the model can capture the ISM features quite well.

A reliable representation of the spatial distribution of dust concentration in the model is essential for examining dust impacts on the ISM rainfall. The modeled AOD at 300, 400, 600 , and $999 \mathrm{~nm}$ are converted to $550 \mathrm{~nm}$ using the Ångström 
(a) TRMM

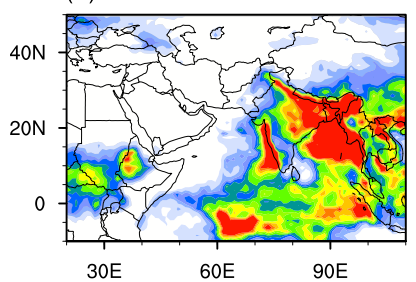

(b) GPCP

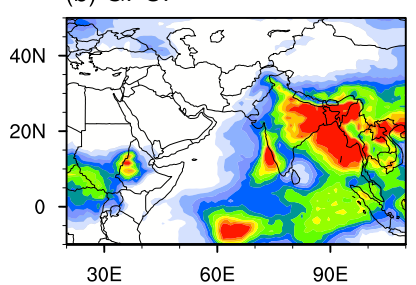

(c) WRF-Chem (ALLF)

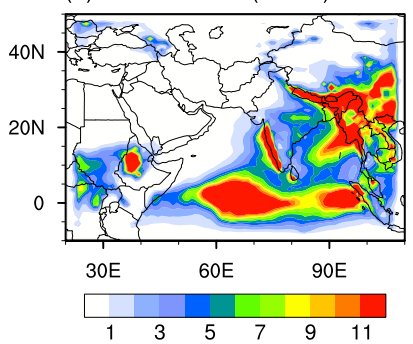

(d) ERA-I

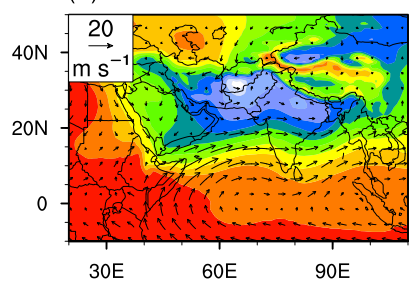

(e) MERRA

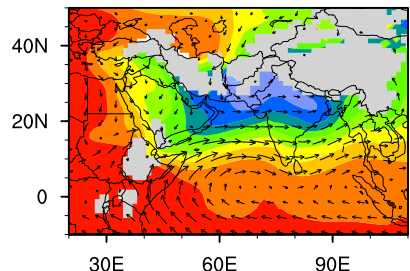

(f) WRF-Chem (ALLF)

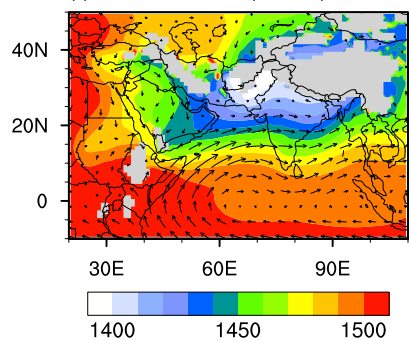

Figure 2. Left: precipitation $\left(\mathrm{mmday}^{-1}\right)$ from (a) TRMM, (b) GPCP, and (c) WRF-Chem (ALLF). Right: $850 \mathrm{hPa}$ GPH (shading; unit: $\mathrm{m}$ ) and wind (arrows; units: $\mathrm{m} \mathrm{s}^{-1}$ ) from (d) ERA-I, (e) MERRA, and (f) WRF-Chem (ALLF). All variables are average for JJA 2008. In (e) and (f), topography is marked out in gray.

exponent and evaluated using satellite-retrieved AOD, which is usually $550 \mathrm{~nm}$. By tuning the empirical proportionality in Eq. (1) against satellite AOD, the spatial pattern of modelled AOD is quite consistent with multiple satellite retrievals and aerosol reanalysis results. Figure 3 demonstrates that WRF-Chem captures the observed high dust loading in the AP, the Thar Desert, and the IP. However, the model underestimates AOD over the northern AS and overestimates AOD in the southern AP in comparison to the other four data sets. Note that MISR, MODIS Aqua, and MACC show much higher AOD over the AS than the southern AP, whereas modeled AOD shows the opposite. This discrepancy between the modeled and satellite data could be attributed to two potential contributors. First, the assumption regarding dust mass distribution on dust particle size in the MADE-SORGAM aerosol scheme is not suitable for Middle East dust aerosols. In MADE-SORGAM, only $7 \%$ of the mass of total dust emissions are assigned to the accumulation mode, whereas the other $93 \%$ percent goes into the coarse mode; consequently, most dust emissions are deposited quickly in the dust source regions in the AP and only very little is transported long-distance to the AS. However, in the Mineral Dust Entrainment and Deposition model (Zender et al., 2003a), $17 \%$

(a) MISR

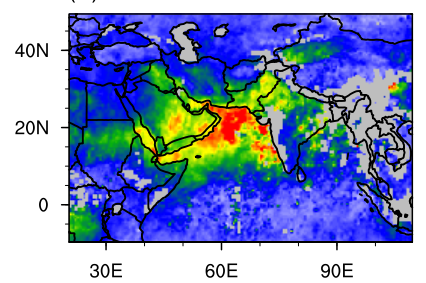

(c) MACC

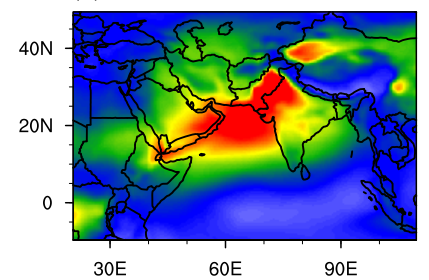

(e) WRF-Chem in ALLF

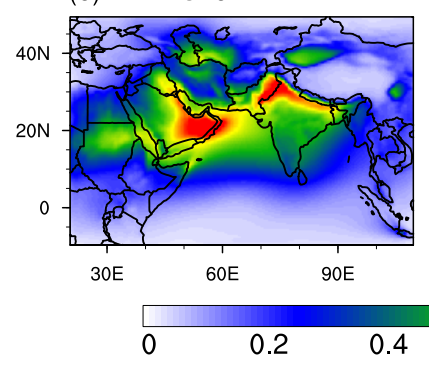

(b) MODIS Aqua

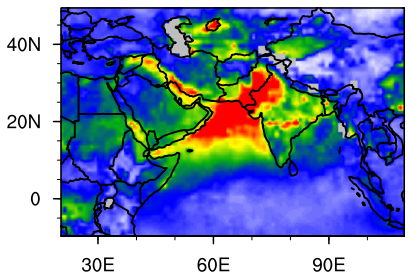

(d) MODIS Terra

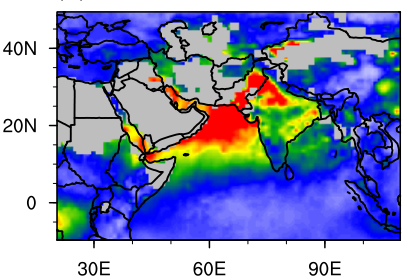

(f) WRF-Chem in NDST

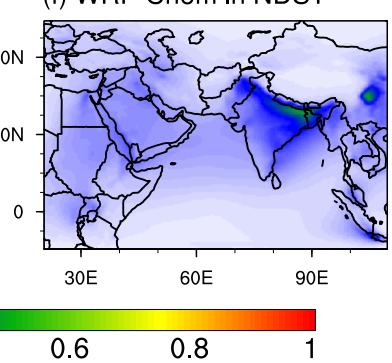

Figure 3. Spatial patterns of AOD (unitless) from (a) MISR $(558 \mathrm{~nm})$, (b) MODIS Aqua $(550 \mathrm{~nm})$, (c) MACC $(550 \mathrm{~nm})$, (d) MODIS Terra $(550 \mathrm{~nm})$, (e) WRF-Chem (ALLF; $550 \mathrm{~nm})$, and (f) WRF-Chem (NDST; $550 \mathrm{~nm}$ ) averaged for JJA 2008. Missing values are marked in gray in (a), (b) and (d).

of the mass of dust emissions are assigned to the accumulation mode. Note also that the underestimation of fine particles reduces dust-induced atmospheric heating because fine particles absorb 3 to 5 times the solar radiation absorbed by coarse particles (Mahowald et al., 2014) and have a longer lifetime. Secondly, the model does not adequately represent the impact of relative humidity on AOD calculations. Increased relative humidity can lead to higher AOD because more water vapor can be taken up by dust particles, an effect known as aerosol humidification (Myhre et al., 2007).

\section{Observed relationship between dust and ISM rainfall}

The observed relationship between AOD and the ISM rainfall is studied using regression analysis. Figure 4 shows the spatial patterns of AOD regressed on the area-averaged ISM rainfall in WHI using their JJA monthly anomalies during 2000 and 2013. Figure 4a shows the regressed AOD using MISR and NOAA observations. Positive anomalies of the ISM rainfall in WHI are associated with heavy aerosol loading over the northern AS, the southern AP, and the IP. This spatial pattern of regressed AOD persists or becomes 

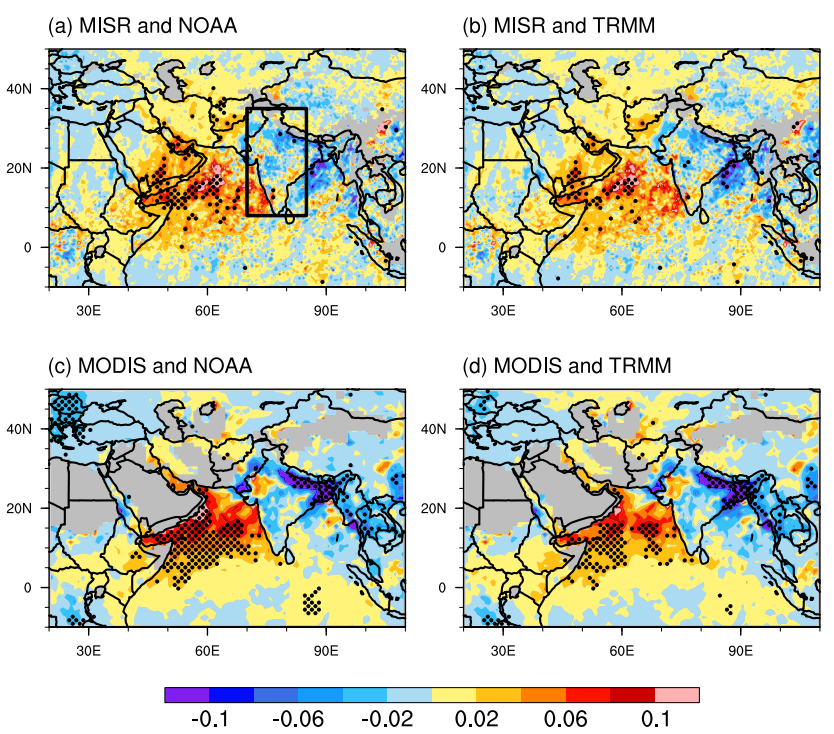

Figure 4. Spatial patterns of AOD regressed on area-averaged ISM rainfall in WHI (box in a) using JJA monthly anomalies from 2000 to 2013. Two different AOD data sets (MISR and MODIS Terra) and two different rainfall data sets (NOAA and TRMM) are used, so there are four different results. The black dots represent grid points that have a $95 \%$ confidence level based on the $t$ test. Missing values are marked out in gray.

stronger in other AOD and rainfall data sets, as shown in Fig. 4b-d. Over northeastern India, dust is negatively correlated with rainfall because local dust is removed through wet deposition. This spatial pattern is consistent with the modeled atmospheric heating pattern induced by dust in Fig. 14a, which will be discussed later.

To evaluate the modeled rainfall responses, the regressed rainfall on the area-averaged AOD in the DST region is calculated based on satellite retrievals, as shown in Fig. 5. In general, the various data sets show a consistent spatial pattern. The positive response of rainfall to AOD is primarily located in the IGP, central India, and CSWI, while a weak negative response is seen in southeast India. These observed north-positive and southeast-negative correlation patterns differ from the results of V2014 (Figure 4b in V2014) and are almost opposite to those of S2015 (Figure 5b in S2015), but are very similar to our observation-based analysis in J2014 (Figure 2c in J2014). See Table 3 for a summary.

The regression analyses of the AOD-ISM rainfall relationship based on observations provide a baseline for evaluating the model results.

\section{Modeled ISM rainfall response to dust}

The ISM rainfall response to the Middle East dust is represented by the ensemble mean differences in rainfall from 16 ALLF and 16 NDST simulations. Figure 6 shows the spatial pattern of rainfall response averaged during JJA 2008. In
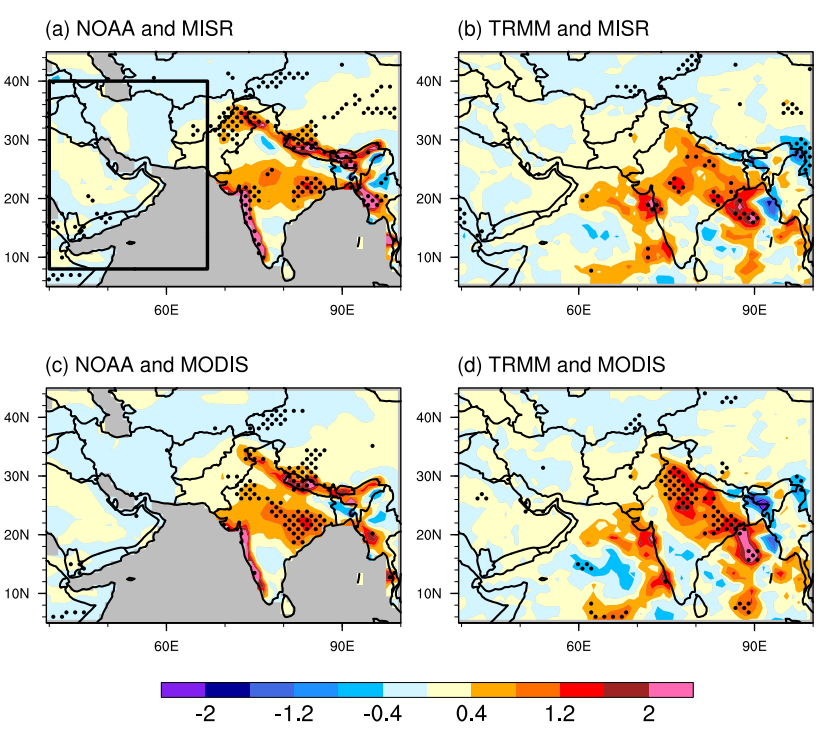

Figure 5. Same as Fig. 4, but for the spatial patterns of precipitation $\left(\mathrm{mm} \mathrm{day}^{-1}\right)$ regressed on area-averaged AOD in the AS, the south AP, and the IP (box in a).

general, rainfall increases over most of India with a magnitude of $0.44 \pm 0.39 \mathrm{~mm} \mathrm{day}^{-1}$ (mean and standard deviation based on ensemble members; about $10 \%$ of the climatology) in WHI. The largest rainfall increases occur in CNI, northern Pakistan, and CSWI. Note that the spatial pattern of rainfall increase closely follows the topography along CSWI and the Tibetan Plateau, indicating that increased rainfall can be mainly related to large-scale circulation changes, which is consistent with the finding that large-scale circulations play a more important role than local soil moisture in modulating the ISM rainfall (Wei et al., 2015). Conversely, decreased rainfall is simulated in southeastern and northeastern India. The spatial pattern of the modeled rainfall response is generally consistent with the observed AOD-ISM rainfall relationship in Figures 5 and 2c in J2014 (Table 3).

Figure $7 \mathrm{a}$ shows the spatial correlations between the regressed rainfall pattern in Figure $5 \mathrm{c}$ and rainfall responses in each of the 16 ensemble pairs (ALLF minus NDST) as well as their ensemble mean. It can be seen that 15 out of 16 members show positive spatial correlations between the modeled rainfall response and regressed rainfall in observations, with a magnitude of 0.1 to 0.5 , which indicates that most of the members can capture the observed spatial patterns of dustinduced rainfall changes. Interestingly, the rainfall response from the ensemble mean shows a spatial correlation of about 0.6 , much larger than any other ensemble members. This indicates that the ensemble mean may cancel out and reduce model errors raised from various parameterization schemes.

Figure $7 \mathrm{~b}$ illustrates the centered spatial correlations between the regressed rainfall pattern in Fig. $5 \mathrm{c}$ and the ensemble means of rainfall responses in several subgroups of the ensemble members. Figure $7 \mathrm{~b}$ shows a higher correlation co- 
Table 3. Rainfall response in various regions of India to Middle East dust in this study and others.

\begin{tabular}{cccccc}
\hline \multicolumn{2}{c}{ Reference } & Pakistan & CNI & CSWI & Southeast India \\
\hline \multirow{2}{*}{ This study } & Satellite & + & + & + & - \\
V2014 & Model & + & + & + & - \\
J2014 & Not shown & No change & + & + \\
S2015 & + & + & + & - \\
\hline
\end{tabular}

“+" and "-" represent increased and decreased rainfall, respectively.

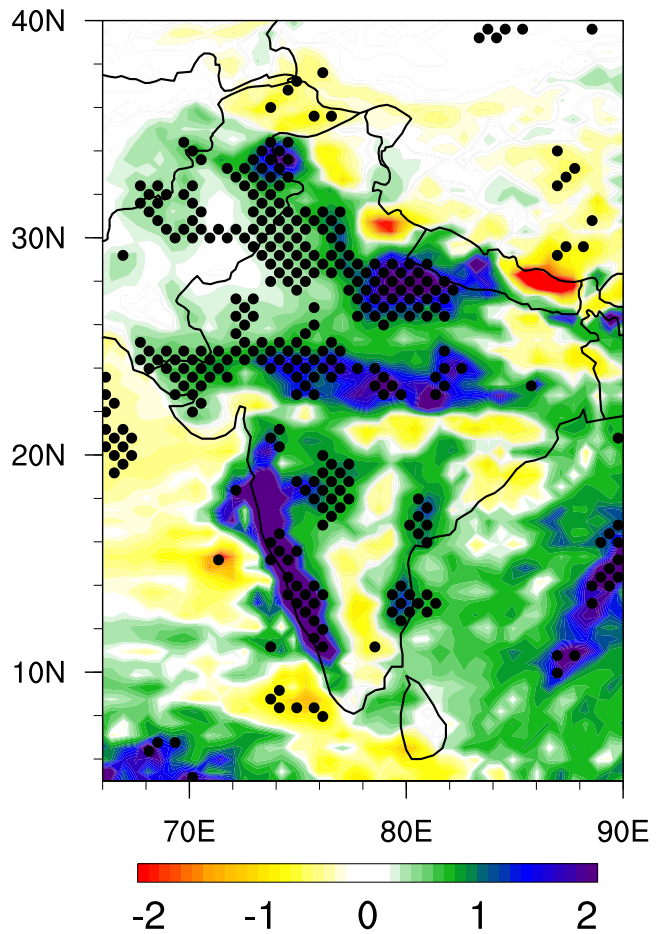

Figure 6. Spatial pattern of WRF-Chem ensemble mean differences in rainfall $\left(\mathrm{mm} \mathrm{day}^{-1}\right)$ between ALLF and NDST experiments during JJA 2008. Areas that have a $90 \%$ confidence level based on a one-sided Student's $t$ test are indicated by dots.

efficient of the regressed rainfall with the ensemble means of the ensemble members using the BouLac PBL scheme (PB8) than those using the YSU scheme (PB1). A higher correlation coefficient is also found when using the RRTMG SW radiation scheme (SW4) than using the Goddard scheme (SW2). However, those correlation coefficients using the different aerosol chemical mixing rules show very few differences.

Figure 8 shows the scatter plot of the area-averaged rainfall in WHI and CNI in each ALLF ensemble member $(y$ axis) against NDST members ( $x$ axis). In WHI, all members are located above or on the 1:1 line except the number 2, indicating that dust-induced rainfall increases are quite robust. Along with the number 2, which shows decreased rainfall, the numbers $4,6,8,10$, and 16 show very weak rain-
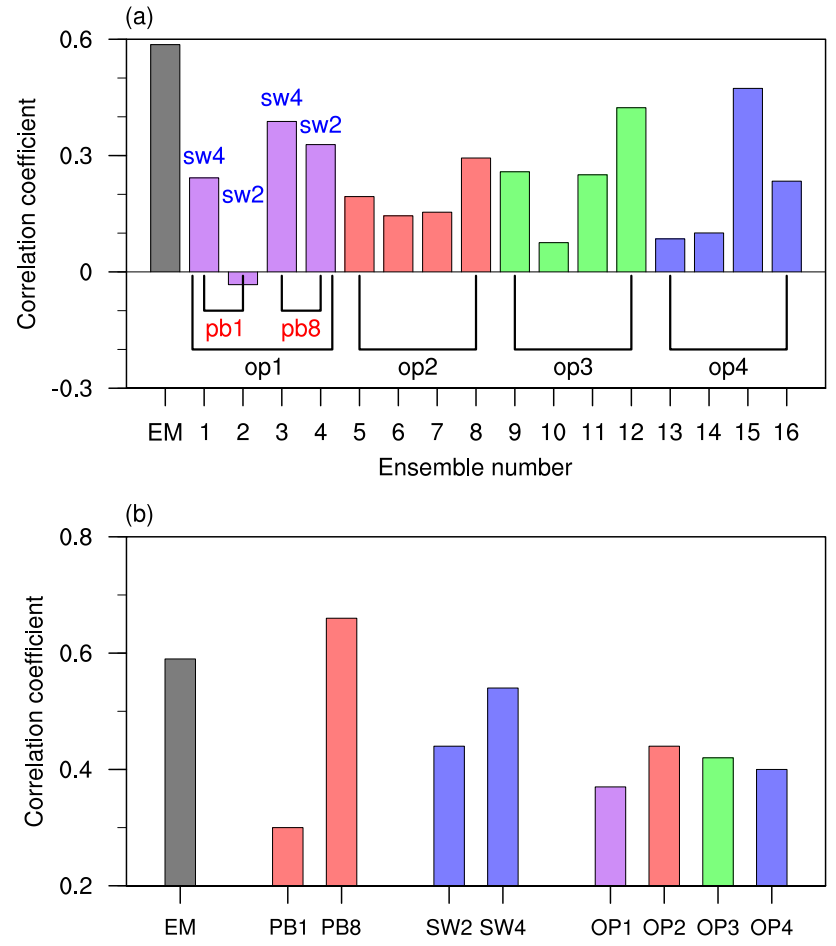

Figure 7. The spatial correlation coefficients between the regressed rainfall change pattern (Figure 5c) and the modeled rainfall response (Fig. 6) in (a) each ensemble member (marked by numbers from 1 to 16), their ensemble mean (marked by "EM"), and (b) the ensemble means of several subgroups of the ensemble members. "EM" stands for the ensemble mean of all ensemble members. In (b), "PB1" and "PB8" indicate the ensemble means of the ensemble members in which PBL option 1 and 8 are used, respectively. "SW2" and "SW4" indicate the ensemble means of the ensemble members in which SW option 2 and 4 are used, respectively. "OP1", "OP2", "OP3", and "OP4" indicate the ensemble means of the ensemble members in which aerosol chemical mixing rules $1,2,3$, and 4 are used, respectively. The region for calculating the spatial correlation is WHI. Using other figures in Fig. 5 for the evaluations gets similar results. See Table 2 for the denotations.

fall increase. These simulations share the same Goddard SW scheme. The situation is similar in CNI, but with more members showing decreased rainfall than in WHI. Therefore, we conclude that the largest effects on our simulation results are 
(a) WHI

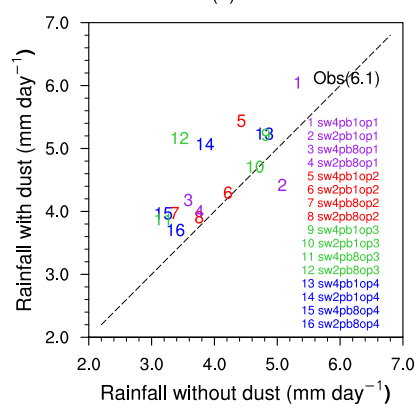

(b) $\mathrm{CNI}$

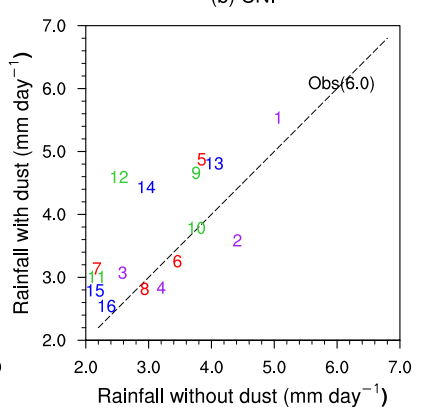

Figure 8. Scatter plot of area-averaged rainfall $\left(\mathrm{mm} \mathrm{day}^{-1}\right)$ in WHI and CNI in 16 pairs of ALLF and NDST ensemble simulations and observations. "Obs" means averaged observational rainfall from TRMM, GPCP, and CMAP, with area-averaged mean values of 6.1 and 6.0 in parentheses in WHI and CNI, respectively. The ensemble numbers are the same as in Fig. 7. See Table 2 for the denotations.

from the PBL scheme, followed by the SW radiation scheme, and the aerosol chemical mixing rule has a very weak effect.

Figure 9 shows the time series of WRF-Chem simulated daily rainfall in each ensemble member and the ensemble mean of rainfall response and AOD in ALLF simulations. In general, the model can capture the temporal variation of rainfall in July and August, with two peaks in early July and the first half of August in both the model runs and observations. The model has a notable low bias in June, which is larger in CNI than in WHI. This low bias could be attributed to irrigation, which occurs in spring and summer with maximum irrigation in May and June in IGP (Douglas et al., 2009). Ensemble means underestimate mean rainfall by one-third in NDST members during JJA 2008 in both WHI and CNI, as shown in Fig. 9. However, the ensemble spread (shadings in light blue and red in Fig. 9a and b) do overestimate rainfall during specific days in WHI and CNI. The daily ensemble mean of rainfall response is shown in Figures $9 \mathrm{c}$ and $9 \mathrm{~d}$. In both WHI and CNI, increased rainfall is illustrated in most days during the entire period. However, the rainfall response does not change significantly in CNI until late June or early July, which is due to a late monsoon onset in CNI at the end of June (Moron and Robertson, 2014). The daily ensemble mean of the modeled area-averaged AOD in DST is also shown in Figures $9 \mathrm{c}$ and $9 \mathrm{~d}$ for comparison with the rainfall response.

Figure 10 shows the cross-correlation between the daily ensemble mean of rainfall response in WHI and CNI and dust AOD (ALLF minus NDST) in DST. Both correlation coefficients become significant when dust AOD leads rainfall response by 10 to 11 days, generally consistent with the observed 13-day lag shown in J2014. This provides further evidence for the causal relationship between Middle East dust and ISM rainfall.

(a) WHI
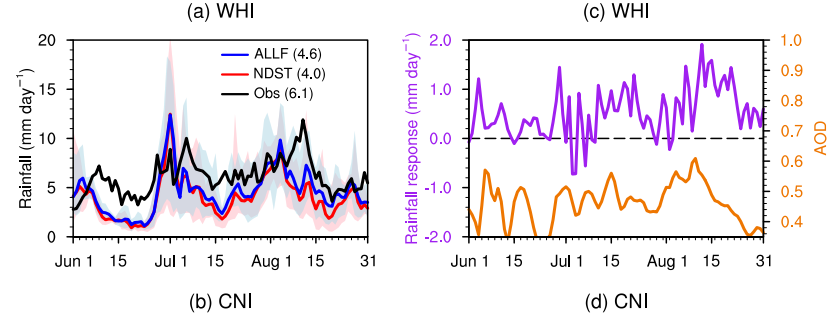

(d) $\mathrm{CNI}$
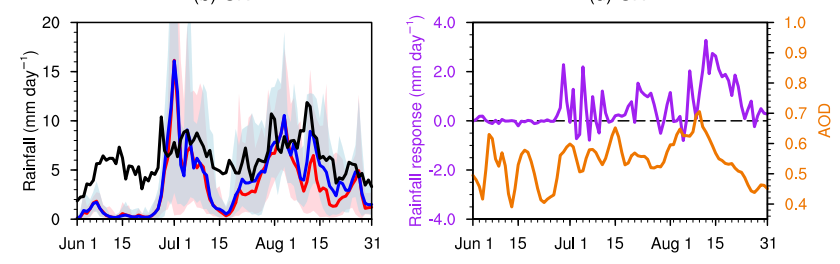

Figure 9. Left: time series of rainfall $\left(\mathrm{mmday}^{-1}\right)$ in ensemble means of ALLF and NDST experiments and rainfall spread of all 32 ensemble members. Right: ensemble mean rainfall responses $\left(\mathrm{mm} \mathrm{day}^{-1}\right)$ in WHI, and CNI and AOD in DST (from ALLF). Light blue and red colors represent the spread of rainfall in ALLF and NDST members, respectively. The numbers in parentheses are time-averaged rainfall.

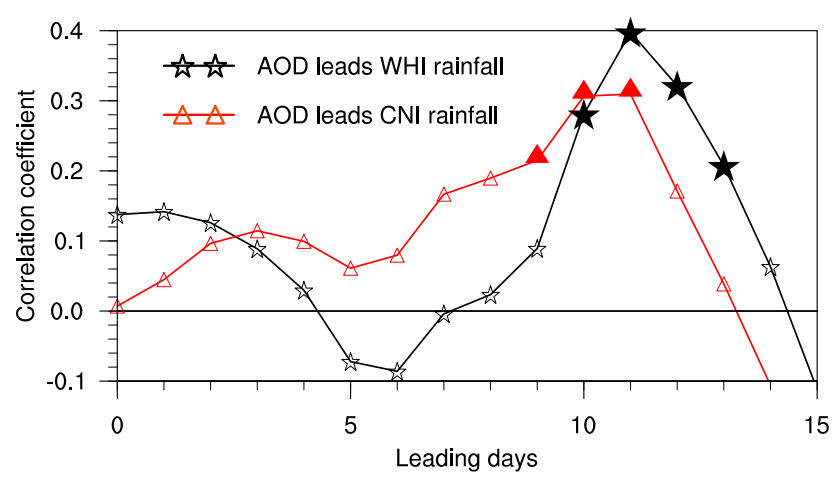

Figure 10. Cross-correlation coefficients between WRF-Chem simulated rainfall responses in WHI and CNI and dust AOD (ALLF minus NDST) in remote DST regions. All correlations are calculated based upon daily anomalies obtained by subtracting the 21-day running mean from the daily data. The filled markers represent that the correlation coefficients with a $95 \%$ confidence level based on the $t$ test. The unfilled markers are not significant.

\section{Physical mechanism of AOD-ISM relationship}

\subsection{Radiative effect of dust}

The direct radiative forcing of dust at all-sky conditions is calculated at the top of the atmosphere (i.e., $50 \mathrm{hPa}$; hereafter TOA), in the atmosphere (i.e., the atmospheric layers between TOA and the surface), and at the surface. Figure 11 shows the ensemble mean of dust radiative forcing (ALLF minus NDST) for SW, LW, and net (SW + LW) radiation. For SW, dust aerosols at TOA reflect and scatter more SW radiation back to space than dust-free cases, so the SW radia- 
tive forcing is negative as shown in Figure 11a (downward radiation is defined as positive). The negative SW radiative forcing at TOA is very strong over water bodies, such as the Red Sea, the AS, the Persian Gulf, and the Caspian Sea, with a magnitude around $30 \mathrm{~W} \mathrm{~m}^{-2}$. However, Fig. 11a shows a quite weak or even positive $\mathrm{SW}$ radiative forcing at TOA over regions with bright surfaces, such as in eastern North Africa, the AP, the IP, and the Taklamakan Desert. The contrasting spatial patterns of SW radiative forcing at TOA over water and land are due to the high surface albedo contrast between them. Because of the high albedo of dust layers, when dust plumes reach the ocean, they reflect and scatter more SW radiation back to space than water bodies would do at the clearsky conditions. Note that the small and sparsely distributed positive SW radiative forcing at the TOA is due to changes in clouds, which can be caused by dust-induced changes in atmosphere dynamics and cloud microphysics. In the atmosphere, dust aerosols can absorb SW radiation and heat the atmosphere. Figure $11 \mathrm{~b}$ shows a positive $\mathrm{SW}$ radiative effect in the atmosphere over the entire domain. This positive radiative effect can attain a magnitude of 20 to $25 \mathrm{~W} \mathrm{~m}^{-2}$ in Iraq, the southern AP, the northern AS, and Pakistan. The land-ocean contrast in radiative forcing observed at the TOA is not seen within the atmosphere, because the spatial distribution of dust-induced atmospheric heating is mainly determined by dust concentration rather than surface properties. However, some studies have proposed that dust aerosols can absorb SW radiation more effectively over bright surfaces than over dark surfaces due to multiple reflections of SW radiation between overlying dust layers and bright land surfaces (Lau et al., 2006; Kuhlmann and Quaas, 2010). At the surface, dust aerosols block SW radiation from reaching the surface through scattering and absorption, which results in a surface cooling effect as shown in Fig. 11c. The maximum magnitude of the negative SW radiative forcing is about $30 \mathrm{~W} \mathrm{~m}^{-2}$ in the Red Sea, the southern AP, the northern AS, the Persian Gulf, and Pakistan.

For LW, at the TOA, Fig. 11d shows that dust causes positive radiative forcing between 1 and $5 \mathrm{~W} \mathrm{~m}^{-2}$. The dust layer can absorb surface-emitted LW radiation, and then reemit it back to the surface. Because the dust layer is cooler than the surface due to its higher altitude, it emits less LW radiation to space than the surface on dust-free days, resulting in positive radiative forcing at the TOA. In the atmosphere, due to the blocking effect of dust, less LW radiation is absorbed by the atmosphere above the dust layer, which results in an atmospheric cooling effect. Figure 11e illustrates that the LW cooling effect of dust in the atmosphere can reach magnitudes of $10 \mathrm{~W} \mathrm{~m}^{-2}$ in dust source regions and decreases to $5 \mathrm{~W} \mathrm{~m}^{-2}$ in most other regions except for the northern Indian Ocean and the Bay of Bengal, where positive forcing is observed. At the surface, the blocking effect of dust results in a positive forcing, i.e., warming effect, of about $10 \mathrm{~W} \mathrm{~m}^{-2}$ over the AP and Indian subcontinent as shown in Fig. 11f. Note that the LW radiative forcing in the atmosphere and at
Table 4. Area-averaged direct radiative forcing of dust simulated by WRF-Chem over the entire model domain for JJA 2008 at all-sky and cloudy conditions. Downward radiation is defined as negative. The acronyms have the same meaning as in Fig. 11. Units: $\mathrm{W} \mathrm{m}^{-2}$.

\begin{tabular}{lrr|rr|rr}
\hline & \multicolumn{2}{c|}{ SW } & \multicolumn{2}{c|}{ LW } & \multicolumn{2}{c}{ Net } \\
\cline { 2 - 7 } & All-sky & Cloudy & All-sky & Cloudy & All-sky & Cloudy \\
\hline TOA & -3.41 & -0.03 & 1.13 & 0.44 & -2.28 & 0.41 \\
ATM & 6.50 & 0.29 & -1.56 & 0.40 & 4.94 & 0.68 \\
BOT & -9.91 & -0.32 & 2.69 & 0.04 & -7.22 & -0.28 \\
\hline
\end{tabular}

the surface is stronger over land than over the ocean. There are several reasons for this. First, the LW radiation interacts more efficiently with large particles than small particles. Large particles are mainly located in dust source regions and very few can be transported over a long distance to the ocean. Secondly, there is less water vapor between the surface and dust layer over land than over the ocean. This strengthens the interactions between surface-emitted LW radiation and overlying dust aerosols. Third, the warmer land surface can emit more LW radiation than the cooler ocean surface.

It is obvious that the LW and SW radiative effects of dust have opposite signs, and the SW forcing has a much greater magnitude than LW forcing (Fig. 11a-f). Therefore, the dust net radiative forcing is dominated by the SW forcing (Fig. 11g-i). The area-averaged radiative forcing of dust over the entire domain is summarized in Table 4. By simple comparison of values in Table 4, we can conclude that a quarter to one-third of the SW radiative forcing is counterbalanced by $\mathrm{LW}$ radiative effects, which is consistent with a previous study (Huang et al., 2009).

\subsection{Radiative effect of clouds}

Figure 12 shows the ensemble means of cloud fraction responses (ALLF minus NDST) between various atmospheric layers to Middle East dust aerosols in JJA 2008. Cloud fraction in the entire atmospheric column (i.e., $1000-50 \mathrm{hPa}$ ) increases in the north Indian Ocean, Somalia, the north Arabian Sea, CSWI, northwest India, and the Bay of Bengal from a magnitude of 0.02 to 0.05 (Fig. 12a). In contrast, it decreases in magnitude in the central Arabian Sea and Sudan from 0.01 to 0.04 . Figure $12 \mathrm{~b}$ illustrates the similar spatial patterns of the cloud fraction responses in the lower troposphere (i.e., $1000-700 \mathrm{hPa}$ ) to those in the entire atmospheric column, but with a larger magnitude and larger significant areas in CSWI and northwest India. However, cloud fraction changes in the middle troposphere (i.e., $700-500 \mathrm{hPa}$; Fig. $12 \mathrm{c}$ ) is very small. Figure 12d demonstrates increased magnitude of the cloud fraction in the upper troposphere (i.e., 500-200 hPa) in the western part of the north Indian Ocean, Somalia, and the Bay of Bengal from 0.02 to 0.04 (Fig. 12d). Cloud fraction responses in the stratosphere (i.e., $200-50 \mathrm{hPa}$ ) are similar to those in the upper troposphere (Fig. 12e). 
(a) SW_TOA (+ downward)

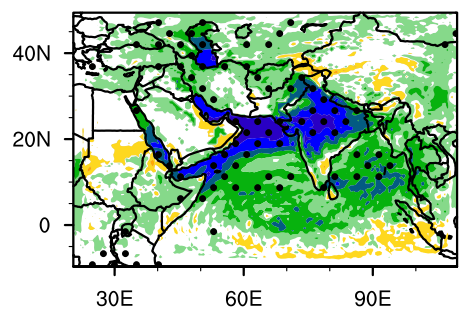

(b) SW_ATM (+ warming)

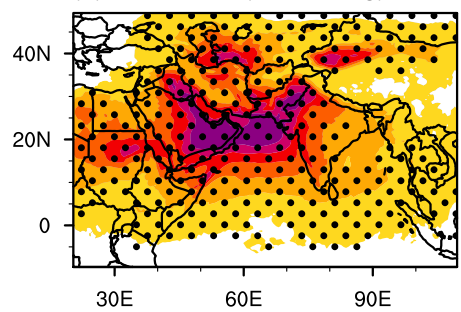

(c) SW_BOT (+ downward)

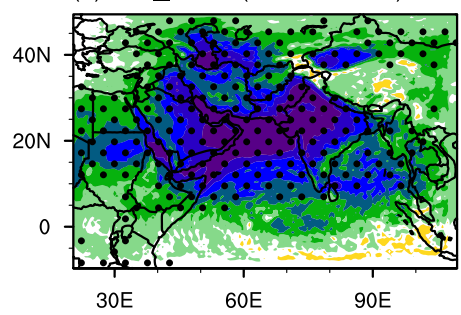

(d) LW

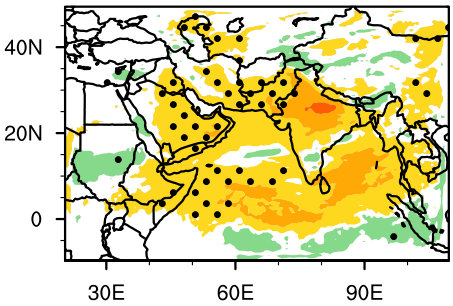

(e) LW

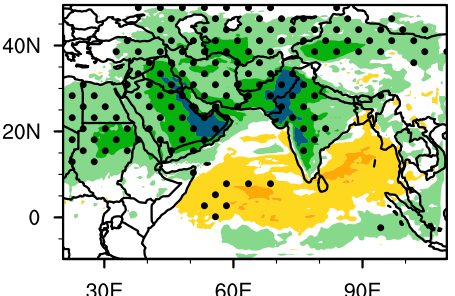

(f) LW

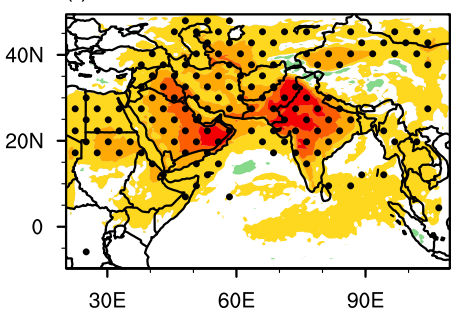

(g) Net

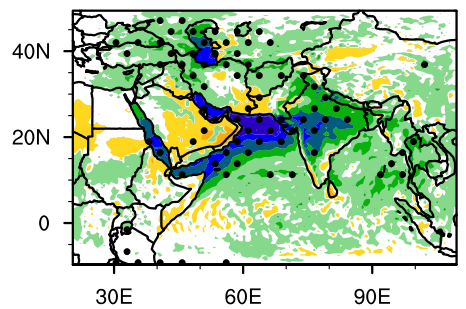

(h) Net

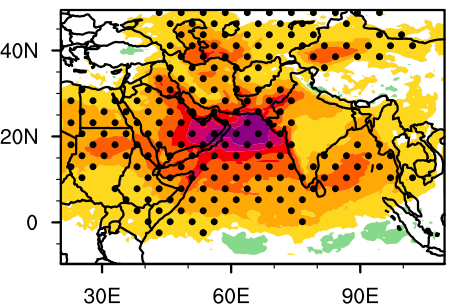

(i) Net

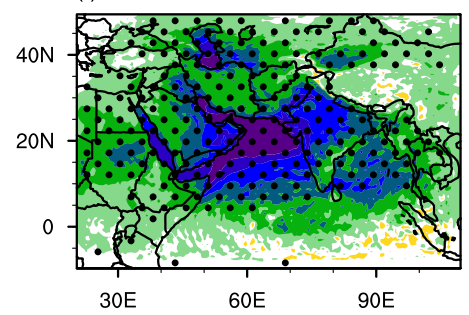



Figure 11. Spatial patterns of dust direct radiative forcing $\left(\mathrm{W} \mathrm{m}^{-2}\right)$ at the top of the atmosphere (TOA), in the atmosphere (ATM), and at the surface (BOT) averaged during JJA 2008 at all-sky conditions. Calculated from the ensemble mean differences between ALLF and NDST experiments. Downward radiation is defined as positive at the TOA and the surface; therefore, positive (negative) value means absorb/warming (irradiate/cooling) effects in the atmosphere. Net radiative effect is the sum of SW and LW radiative effect. The dotted areas indicate that the radiative effect has a $95 \%$ confidence level based on a one-sided Student's $t$ test.

Figure 13 illustrates the radiative effects at various atmospheric layers due to changes in cloud fraction calculated by subtracting the radiative effects at the clear-sky conditions from those at the all-sky conditions. The SW radiative effect at TOA decreases (Fig. 13a) in areas where cloud fraction in the entire atmospheric column increases (Fig. 12a), which is because more cloud can scatter more SW radiation to space. Increased SW radiation at TOA is also seen in the central Arabian Sea and Sudan where cloud fraction decreases. At the surface, the spatial distribution of the SW radiative effect displays a very similar pattern to that at TOA, but with a smaller magnitude (Fig. 13c), which results in a positive radiative effect in the atmosphere (Fig. 13b) over the north Arabian Sea and CSWI. The LW radiation increases at TOA (Fig. 13d) in areas where cloud fraction in the upper troposphere or stratosphere increases, because clouds emit less LW radiation to space than the surface due to their lower temperature. At the surface, the LW radiation effect is determined by changes in cloud fraction in the lower tropo- sphere through a cloud blocking effect of LW radiation from the surface, which decreases in the central Arabian Sea and increases in the Indian subcontinent (Fig. 13f). Figure 13e shows the increased LW radiation effect in the south Arabian Sea. Figure $13 \mathrm{~g}-\mathrm{i}$ demonstrate the net $(\mathrm{LW}+\mathrm{SW})$ radiative effect. At TOA and the surface, the spatial pattern of the net radiative effects is dominated by $\mathrm{SW}$ radiative effects. However, in the atmosphere, the net radiative effect is determined by both SW and LW radiative effects. The area-averaged radiative effects due to cloud are summarized in Table 4, showing that cloud response contributes about $14 \%$ to the total radiative effect (warming) in the atmosphere, which amplifies the aerosol-induced atmospheric heating effect.

\subsection{Dust impact on circulation}

Dust aerosols can change large-scale circulations through their surface cooling effects and atmospheric warming ef- 
(a) $1000-50 \mathrm{hPa}$

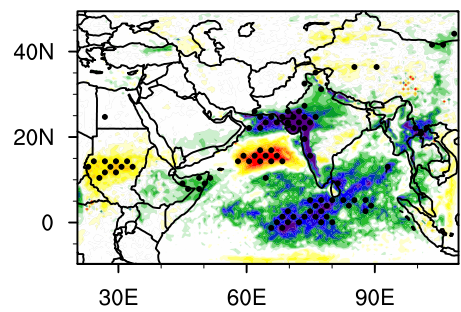

(d) $500-200 \mathrm{hPa}$

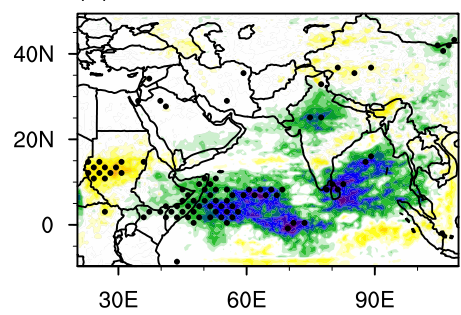

(b) $1000-700 \mathrm{hPa}$

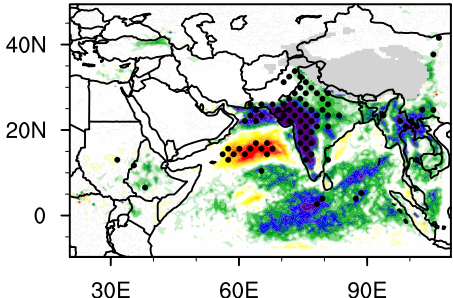

(e) $200-50 \mathrm{hPa}$

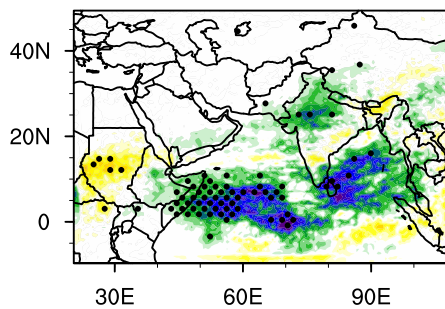

(c) $700-500 \mathrm{hPa}$
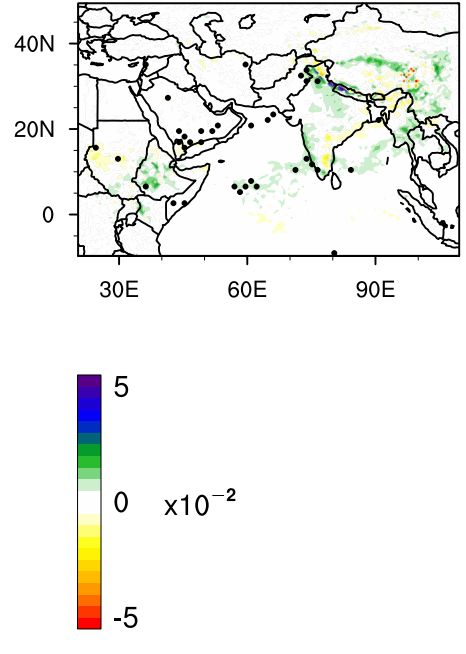

Figure 12. Spatial patterns of the ensemble means of cloud fraction responses (ALLF minus NDST; scale factor: $10^{-2}$ ) for JJA 2008 between various atmospheric layers. The dots indicate where cloud fraction responses have a $95 \%$ confidence level based on a one-sided Student's $t$ test.

(a) SW_TOA (+ downward)

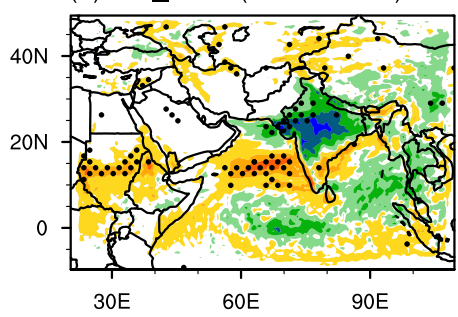

(b) SW_ATM (+ warming)

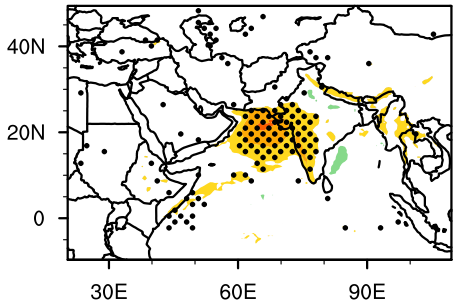

(c) SW_BOT (+ downward)

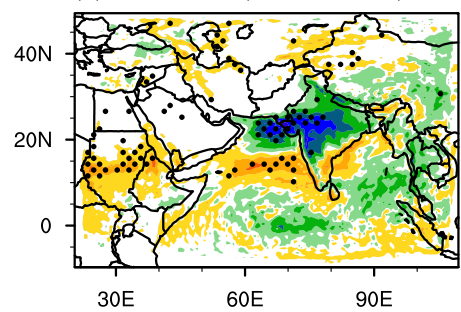

30E (d) LW

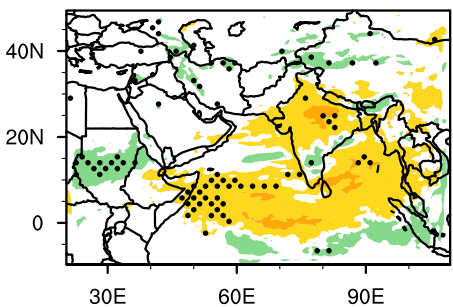

(e) LW

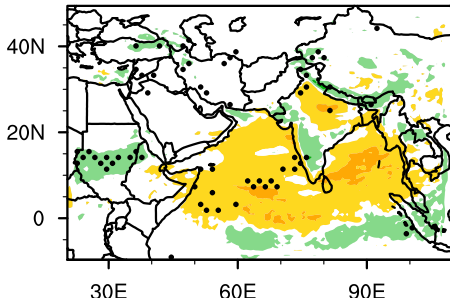

(f) LW

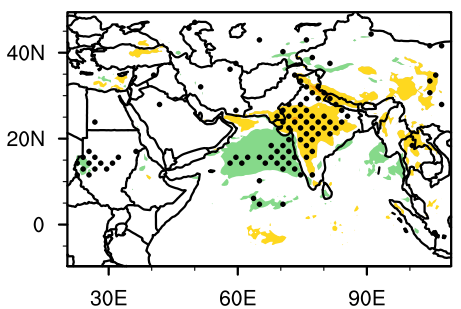

(g) Net

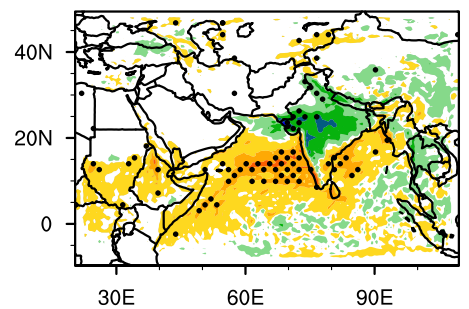

(h) Net

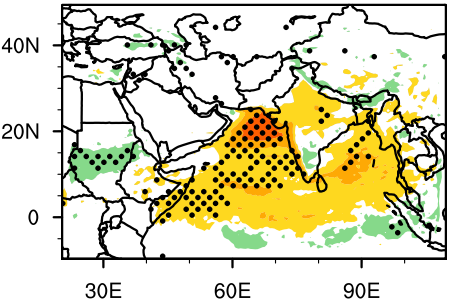

(i) Net

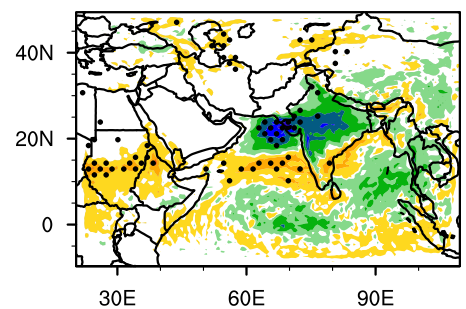

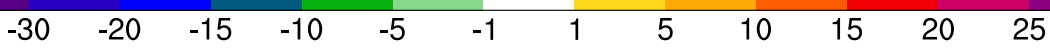

Figure 13. Same as Fig. 11, but for radiative effects $\left(\mathrm{W} \mathrm{m}^{-2}\right)$ at cloudy conditions, calculated as radiative effects at all-sky conditions minus those at clear-sky conditions. 

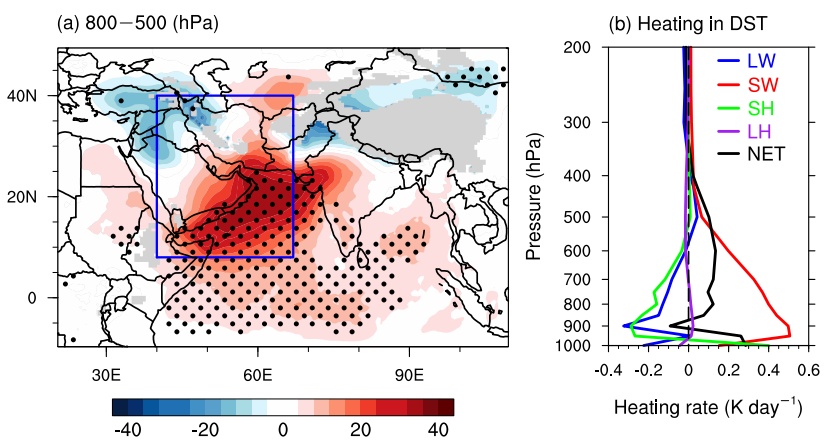

Figure 14. (a) Spatial pattern of the ensemble mean differences in thickness between 800 and $500 \mathrm{hPa}$ pressure layers between the ALLF and NDST experiments (unit: $m$ ). (b) Vertical profiles of the ensemble mean differences in atmospheric heating rate areaaveraged in DST (box in a) between the ALLF and NDST experiments (units: $\mathrm{Kday}^{-1}$ ). The dots in (a) indicate that the radiative effect has a $95 \%$ confidence level based on a one-sided Student's $t$ test. All heating rates are for all-sky conditions. "SH", "LH", and "NET" stand for sensible heating, latent heating, and net heating rate. Net heating is the sum of SW, LW, SH, and LH.

fects. The resultant circulation change depends on the net effect of the two.

Figure 14a illustrates the spatial pattern of the ensemble mean thickness differences in ALLF and NDST simulations between 800 and $500 \mathrm{hPa}$ averaged for JJA 2008. According to the hypsometric equation, the thickness between two isobaric surfaces is proportional to the mean temperature of the layer. Figure 14a illustrates the increased thickness over the AS and southeast AP from a magnitude of 15 to $25 \mathrm{~m}$. The spatial pattern of the thickness differences generally follows the AOD spatial pattern (Fig. 3e). Figure 14b shows the vertical profiles of area-averaged atmospheric heating sources at all-sky conditions in DST. LW radiative forcing and sensible heating contribute to the atmospheric cooling from the surface to about $600 \mathrm{hPa}$. The $\mathrm{SW}$ radiative forcing is the only source of atmospheric warming effect, which is strongest near $950 \mathrm{hPa}$ and diminishes to zero near $400 \mathrm{hPa}$. The latent heat shows few changes. Net atmospheric heating, which is the sum of LW, SW, sensible heat, and latent heat, demonstrates the atmospheric heating effect of dust from the near surface to $400 \mathrm{hPa}$ except for an anomalous cooling effect at $900 \mathrm{hPa}$, which is caused by cloud effects.

Dai et al. (2013) showed that the south-north ocean-land thermal contrast in the mid-upper troposphere is more important for the ISM formation than in the lower troposphere. The dust-induced atmospheric heating in the mid-upper troposphere is studied by selecting two subgroups of simulations with "wet" and "dry" rainfall responses in the WHI region. The ensemble members in the "wet" and "dry" are selected based on the rainfall responses in Fig. 8a, and include ensemble members of $1,5,12$, and 14 , and 2, 4, 6, and 8 , respectively. Figure 15 shows the temperature responses
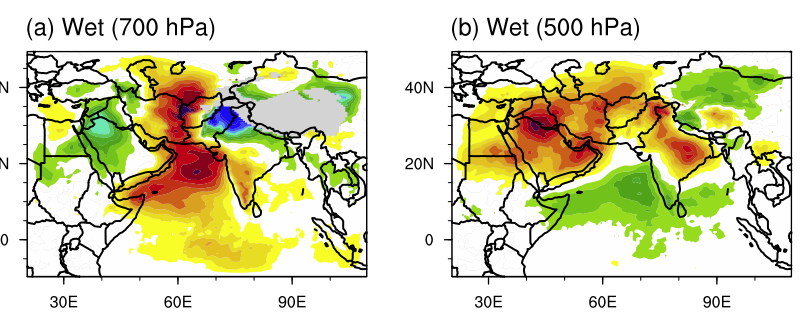

(c) Dry $(700 \mathrm{hPa})$

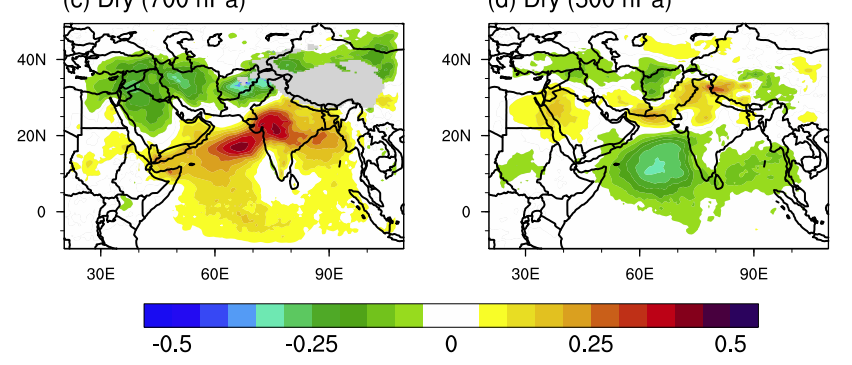

Figure 15. Spatial patterns of WRF-Chem simulated temperature differences (ALLF minus NDST; unit: K) in the "wet" subgroup at (a) $700 \mathrm{hPa}$ and (b) $500 \mathrm{hPa}$, and in the "dry" subgroup at (c) $700 \mathrm{hPa}$ and (d) $500 \mathrm{hPa}$. The ensemble members in the "wet" and "dry" subgroups are selected based on the rainfall responses in Fig. 8a, and include ensemble members of 1, 5, 12, and 14, and 2, 4, 6 , and 8 , respectively. No significant test is applied due to the small sample size of four.

at 700 and $500 \mathrm{hPa}$ in the "wet" and "dry" subgroups. The dust-induced atmospheric heating at $700 \mathrm{hPa}$ is strong over the Iranian Plateau and the Arabian Sea in the "wet" members, which is consistent with the observational results in Jin et al. (2014), but the "dry" members show very weak heating or even a cooling effect. Furthermore, the dust-induced high-level (i.e., $500 \mathrm{hPa}$ ) heating, also known as the "EHP" effect, has a larger spatial coverage than the low-level (i.e., $700 \mathrm{hPa}$ ) heating and is mainly located in the Iranian Plateau rather than the Tibetan Plateau, which is different from the original "EHP" hypothesis proposed by Lau et al. (2006).

Due to dust-induced atmospheric heating in the troposphere, a low-pressure system at $850 \mathrm{hPa}$ can be observed (shown as contours in Fig. 16a) over the AS, shamal wind regions, the IP, and the Caspian Sea and nearby regions. A convergence region centered over the north AS and western India at $850 \mathrm{hPa}$ is associated with the low-pressure system, illustrated by arrows in Fig. 16a. In this convergence area, the strengthened southwesterly winds transport more water vapor from the AS northeastward to the Indian subcontinent. When moist airflows meet the mountains in CSWI, CNI, the Tibetan Plateau, and north Pakistan, they are lifted, converged and cooled, which forms the orographic rainfall (Fig. 6). Additionally, the strengthened northwesterly winds over the AP can result in more dust emissions over the AP and transport them from the AP to the AS, thus forming a positive feedback. Figure 16b shows that dust can also modulate the atmospheric circulation in the upper troposphere, 
(a) $850(\mathrm{hPa})$

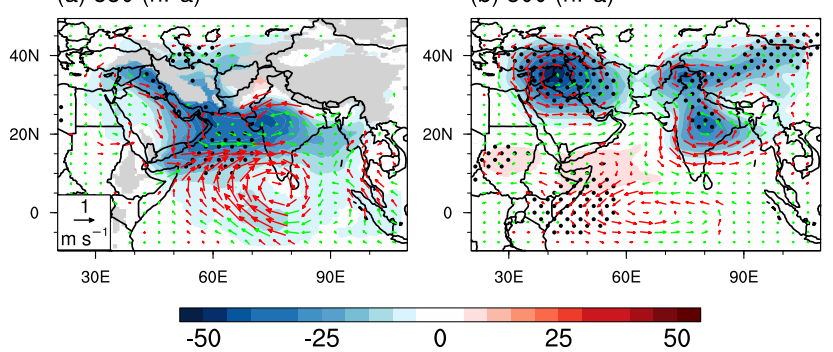

Figure 16. Spatial patterns of WRF-Chem ensemble mean differences in GPH (shading; unit: $\mathrm{m}$ ) and winds (arrows; units: $\mathrm{m} \mathrm{s}^{-1}$ ) at (a) $850 \mathrm{hPa}$ and (b) $500 \mathrm{hPa}$ between ALLF and NDST experiments. The dotted areas show a $95 \%$ confidence level based on a one-sided Student's $t$ test. The red arrows show wind differences that have a $95 \%$ confidence level based on a one-sided Student's $t$ test, and green arrows are other wind differences (no confidence).

e.g., $500 \mathrm{hPa}$. There are two dust-induced convergence regions at $500 \mathrm{hPa}$ : the IP and Iraq, CNI and North China.

\subsection{Dust impact on moisture transport}

By disturbing large-scale circulations, dust can also modulate the moisture transport of ISM. Shadings in Fig. 17a show the spatial distribution of the ensemble mean of precipitable water differences in the entire atmospheric column in ALLF and NDST experiments during JJA 2008. Increased precipitable water $(\mathrm{PW})$ is simulated over the entire Indian subcontinent with maximum increases of $2 \mathrm{~mm}$ in CSWI and IGP. The increased PW is attributed to the strengthened moisture transport by the southwesterly winds over the AS and southeasterly winds over the IGP, as indicated by arrows in Fig. 17a. A minor PW increase occurs in east India around $20^{\circ} \mathrm{N}$, which causes decreased rainfall in this area as shown in Fig. 6. Note that the increased PW is less than the increased rainfall in CSWI and central India. This is because the rainfall process usually involves moisture convergence, which brings in moisture from surrounding regions (Trenberth, 1999). The moisture flux integrated in the lower troposphere (i.e., 1000-700 hPa) shows little difference compared with that integrated in the entire atmospheric column. Furthermore, the moisture flux integrated in the upper troposphere (i.e., 500-200 hPa) has a much smaller magnitude than that in the lower troposphere (about $5 \%$ ). Therefore, they are not shown in this study.

\subsection{Dust impact on moist static energy}

The maximum moist static energy (MSE) in the sub-cloud layer has been demonstrated to be closely related to the poleward boundary of the monsoon circulation and rainfall (Prive and Plumb, 2007a, b). Following the method of Wang et al. (2009), the mean MSE is calculated in the three lowest model layers to represent the sub-cloud MSE. Figure 17b (a)

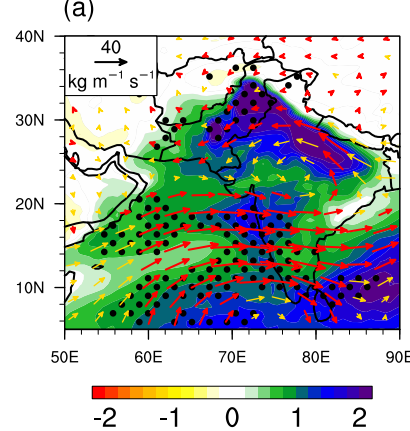

(b)

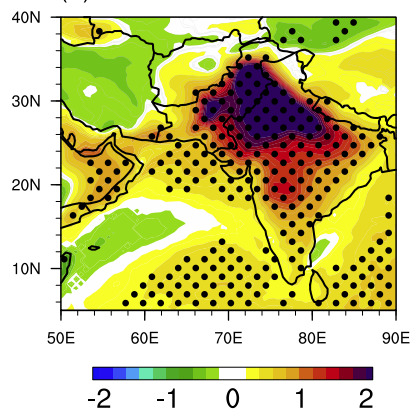

Figure 17. Spatial patterns of WRF-Chem ensemble mean differences in (a) precipitable water (shading; unit: $\mathrm{mm}$ ) and water vapor flux (arrows; units: $\mathrm{kg} \mathrm{m}^{-1} \mathrm{~s}^{-1}$ ) both integrated within the entire atmospheric column and (b) moist static energy (units: $\mathrm{kJ} \mathrm{kg}^{-1}$ ) in the three lowest model layers. Black dots represent the differences in precipitable water and moist static energy that have a $95 \%$ confidence level based on a one-sided Student's $t$ test. The red arrows represent wind differences that have a $95 \%$ confidence level, and the gold arrows represent other wind differences (no confidence).

shows the spatial distribution of the ensemble mean of MSE differences between ALLF and NDST experiments for JJA 2008. We found increased MSE in Pakistan and India, with a magnitude between 1 and $2 \mathrm{~kJ} \mathrm{~kg}^{-1}$. The maximum increase of MSE is co-located with changes in precipitation and precipitable water in the IGP region. The spatial distribution and magnitude of the MSE response to Middle East dust in this study is very similar to the MSE changes induced by anthropogenic aerosols in the study of Wang et al. (2009), suggesting the robustness and usefulness of adopting sub-cloud MSE to characterize changes in the ISM system due to desert dust as well as anthropogenic aerosols.

\section{Discussion and conclusions}

Frequent dust storms develop in the boreal summer due to the strong shamal winds in the AP and IP. After long-distance transport, these dust storms can reach the AS and interact with the ISM. Using observational data sets, we found a positive correlation between the ISM rainfall and the remote Middle East dust aerosols. To disclose the physical mechanism responsible for this correlation, a regional meteorological model coupled with online chemistry, WRF-Chem, is used to examine the radiative effects of Middle East dust on ISM. The primary conclusions are drawn below.

WRF-Chem is capable of simulating the major ISM features and heavy dust loading in the Middle East and the AS during the boreal summer. The model can capture the ISM circulations quite well, e.g., the cross-equator circulation and the southwesterly winds over the AS. It also reproduces precipitation patterns quite similar to the observations, with heavy precipitation located in CSWI and IGP. The low 
bias of precipitation in central India is partly attributed to the lack of representation of agriculture irrigation. In addition, by tuning the empirical proportionality constant in the GOCART dust emissions scheme against satellite observations, the model can capture the main spatiotemporal features of dust aerosols in the Middle East and its surrounding regions.

Satellite retrievals show that AOD in DST is positively correlated with the ISM rainfall in CSWI, CNI, and Pakistan. This correlation is examined here by using WRF-Chem. Two groups of experiments with the presence and absence of dust emissions are designed to isolate dust impacts on ISM rainfall. Ensemble model results based on PPCE show that mineral dust increases the ISM rainfall by $0.44 \pm 0.39 \mathrm{~mm} \mathrm{day}^{-1}$ (about $10 \%$ of the climatology) in WHI. The spatial pattern of the modeled rainfall increase is highly consistent with the observational results shown in J2014 and this study, while V2014 and S2015 show different patterns. Using a GCM, V2014 demonstrated significantly decreased rainfall or very weakly increased rainfall in central India. The differences in rainfall response between their studies and ours may be attributed to different atmospheric heating patterns caused by dust (Fig. 14 in this study versus Fig. S4a in V2014), which may result from different representations of dust emissions, dust diffusion in the PBL, or model resolution. An accurate representation of elevated orography of the Tibetan Plateau is critical in simulating the ISM rainfall due to the large elevation gradient (Bollasina et al., 2011). Using an RCM, S2015 shows opposite rainfall responses to those of J2014 and this study. In S2015, the decreased rainfall in CNI is attributed to the high GPH anomalies over CNI, Pakistan, and the central and north AS. Our further analyses show that the modeled rainfall response from the ensemble mean shows a much stronger spatial correlation with the observed rainfall response than any other ensemble members, which indicates that ensemble mean can cancel out and reduce model errors from various parameterizations. By comparing the performance of individual ensemble members in Figs. 7 and 8, we conclude that the largest effects on our simulation results are from the PBL schemes, followed by the SW radiation schemes, and the aerosol chemical mixing rules have a relatively weak effect.

Cross-correlation analysis of the modeled daily dust AOD in DST and the ISM rainfall response in WHI and CNI shows a maximum cross-correlation when dust AOD leads rainfall response by 11 days (Fig. 10). This finding is very similar to the 13 days found in observational data sets by J2014. Note that the model experiments here have separated the rainfall response due to dust for the correlation analysis, while observations include various forcings and responses. Considering that a typical dust event usually lasts 3 to 5 days, and the time for water vapor to be transported from the equator to CNI is about a week, assuming a wind speed of $10 \mathrm{~m} \mathrm{~s}^{-1}$, the total time is about 10 to 12 days. Therefore, the timescale of 11 days is reasonable. This cross-correlation provides further

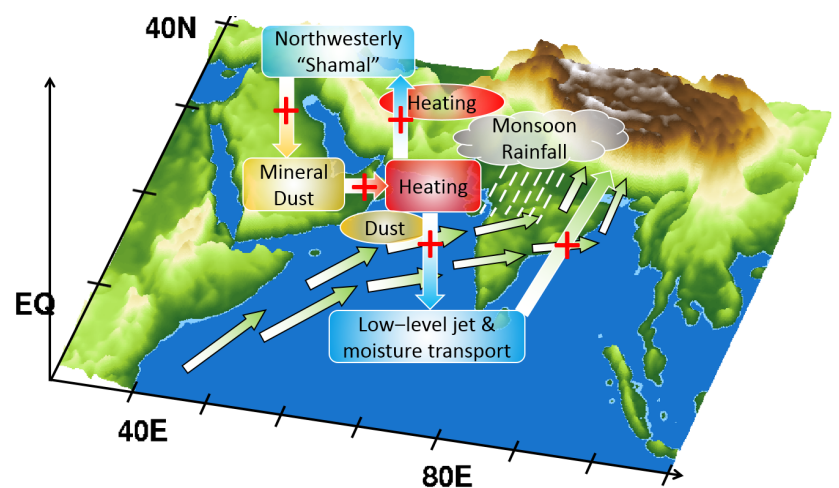

Figure 18. Schematic diagram shows the physical mechanism for the Middle East dust-ISM rainfall connection. Red plus signs represent positive responses. The positive feedback between dust emissions, atmospheric heating, and shamal winds is seen as a cycle over the Middle East and the Arabian Sea.

evidence to support the causal relationship between Middle East dust and ISM rainfall.

Dust-induced ISM rainfall increase can be explained by the dynamic impacts of dust radiative forcing on water vapor transport from the AS to the ISM region. By absorbing solar radiation in the atmosphere (Fig. 11h), dust heats the lower troposphere $(800-500 \mathrm{hPa})$ by about $1 \mathrm{~K}$ over the AS, the south AP, and the IP (Fig. 14). Dust-induced atmospheric heating is further enhanced by the positive radiative effect due to cloud changes, which in turn causes a low-pressure system at $850 \mathrm{hPa}$ over the AS and surrounding regions that is associated with a convergence anomaly over the AS and north India (Fig. 16). The southwestern branch of the convergence anomaly transports more water vapor from the AS to the Indian subcontinent, resulting in more precipitable water in the atmospheric column (Fig. 17a). This strengthened southwesterly wind due to dust-induced heating is responsible for the dust-ISM rainfall correlation observed in both satellite data and model simulations. Furthermore, the northwestern branch of the convergence anomaly over the AP can create more dust emissions and transport these dust particles from the AP to the AS, building a positive feedback. Lastly, Middle East dust aerosols tend to increase the subcloud MSE in the Indian subcontinent by absorbing solar radiation. The overall chains of the physical mechanism are illustrated in a schematic diagram in Fig. 18.

Three issues warrant further discussion. First, the hypothesis of the Middle East dust-ISM rainfall connection largely relies on the dust-induced atmospheric heating, which is primarily determined by the imaginary refractive index of dust aerosols in the climate model. However, the retrieved imaginary refractive index of dust aerosols is found to span a wide range from 0.001 to 0.008 at $600 \mathrm{~nm}$ (e.g., Colarco et al., 2014), while only one constant value (i.e., 0.003) is used in the released version of WRF-Chem model. The uncertainties associated with the dust imaginary refractive index could add 
uncertainties to the rainfall responses in the model simulations. This issue will be examined in more detail in our future studies. Secondly, SST is prescribed during the 3-month simulation period. The SST in the AS has been shown to play an important role in modulating the ISM rainfall (e.g., Levine and Turner, 2012). The surface cooling effect of dust can decrease the SST, which may influence the ISM rainfall response to Middle East dust. Thirdly, the aerosol indirect effect is parameterized only in the microphysics scheme on the grid scale (i.e., stratiform rainfall) in current WRFChem (e.g., Lim et al., 2014), therefore experiments with a relatively coarse horizontal resolution of $54 \mathrm{~km}$ that cannot resolve convective clouds (typically $1-5 \mathrm{~km}$ wide) fails to consider the aerosol indirect effects on the ISM convective rainfall. In future studies, we suggest the use of a highresolution RCM with grid spacing at $1-5 \mathrm{~km}$ coupled with an ocean model to quantify the impacts of dust-induced SST change and aerosol indirect effects on the ISM rainfall. Overall, this study highlights the thermodynamic and hydrological impacts of the remote mineral dust aerosols in the Middle East on the ISM rainfall. This dust-ISM rainfall relationship should be examined in the models participating in the fifth and future phases of the Coupled Model Intercomparison Project on interannual to decadal timescales.

Author contributions. Q. Jin and J. Wei designed the WRF-Chem experiments. Q. Jin carried out all the simulations with contributions from J. Wei and Z.-L. Yang. Q. Jin prepared the manuscript with contributions from all co-authors.

Acknowledgements. This research was supported by King Abdullah University of Science and Technology (KAUST). We wish to thank the Texas Advanced Computing Center for providing powerful computing resources. We also thank Patricia Bobeck and Alex Resovsky for proofreading and Lei Yin for his plotting of the 3-D elevation map in Fig. 18. Thanks to the editor and two reviewers for evaluating this paper.

Edited by: A. B. Guenther

\section{References}

Ackermann, I. J., Hass, H., Memmesheimer, M., Ebel, A., Binkowski, F. S., and Shankar, U.: Modal aerosol dynamics model for Europe: Development and first applications, Atmos. Environ., 32, 2981-2999, 1998.

Albani, S., Mahowald, N. M., Perry, A. T., Scanza, R. A., Zender, C. S., Heavens, N. G., Maggi, V., Kok, J. F., and Otto-Bliesner, B. L.: Improved dust representation in the Community Atmosphere Model, Journal of Advances in Modeling Earth Systems, 6, 541570, 2014.

Barnard, J. C., Fast, J. D., Paredes-Miranda, G., Arnott, W. P., and Laskin, A.: Technical Note: Evaluation of the WRF-Chem
"Aerosol Chemical to Aerosol Optical Properties" Module using data from the MILAGRO campaign, Atmos. Chem. Phys., 10, 7325-7340, doi:10.5194/acp-10-7325-2010, 2010.

Benedetti, A., Morcrette, J. J., Boucher, O., Dethof, A., Engelen, R. J., Fisher, M., Flentje, H., Huneeus, N., Jones, L., Kaiser, J. W., Kinne, S., Mangold, A., Razinger, M., Simmons, A. J., and Suttie, M.: Aerosol analysis and forecast in the European Centre for Medium-Range Weather Forecasts Integrated Forecast System: 2. Data assimilation, J. Geophys. Res.-Atmos., 114, D13205, doi:10.1029/2008JD011115, 2009.

Binkowski, F. S. and Shankar, U.: The Regional Particulate Matter Model .1. Model description and preliminary results, J. Geophys. Res.-Atmos., 100, 26191-26209, 1995.

Bollasina, M. A., Ming, Y., and Ramaswamy, V.: Anthropogenic Aerosols and the Weakening of the South Asian Summer Monsoon, Science, 334, 502-505, 2011.

Bollasina, M. A., Ming, Y., and Ramaswamy, V.: Earlier onset of the Indian monsoon in the late twentieth century: The role of anthropogenic aerosols, Geophys. Res. Lett., 40, 3715-3720, 2013.

Chen, F., Pielke, R. A., and Mitchell, K.: Development and Application of Land-Surface Models for Mesoscale Atmospheric Models: Problems and Promises, in: Land Surface Hydrology, Meteorology, and Climate: Observations and Modeling, edited by: Lakshmi, V., Albertson, J., and Schaake, J., American Geophysical Union, Washington, D.C., doi:10.1029/WS003p0107, 2001.

Chen, M. Y., Xie, P. P., Janowiak, J. E., and Arkin, P. A.: Global land precipitation: A 50-yr monthly analysis based on gauge observations, J. Hydrometeorol., 3, 249-266, 2002.

Colarco, P. R., Nowottnick, E. P., Randles, C. A., Yi, B. Q., Yang, P., Kim, K. M., Smith, J. A., and Bardeen, C. G.: Impact of radiatively interactive dust aerosols in the NASA GEOS-5 climate model: Sensitivity to dust particle shape and refractive index, J. Geophys. Res.-Atmos., 119, 753-786, 2014.

Dai, A. G., Li, H. M., Sun, Y., Hong, L. C., Ho, L., Chou, C., and Zhou, T. J.: The relative roles of upper and lower tropospheric thermal contrasts and tropical influences in driving Asian summer monsoons, J. Geophys. Res.-Atmos., 118, 7024-7045, 2013.

Dee, D. P., Uppala, S. M., Simmons, A. J., Berrisford, P., Poli, P., Kobayashi, S., Andrae, U., Balmaseda, M. A., Balsamo, G., Bauer, P., Bechtold, P., Beljaars, A. C. M., van de Berg, L., Bidlot, J., Bormann, N., Delsol, C., Dragani, R., Fuentes, M., Geer, A. J., Haimberger, L., Healy, S. B., Hersbach, H., Holm, E. V., Isaksen, L., Kallberg, P., Kohler, M., Matricardi, M., McNally, A. P., Monge-Sanz, B. M., Morcrette, J. J., Park, B. K., Peubey, C., de Rosnay, P., Tavolato, C., Thepaut, J. N., and Vitart, F.: The ERA-Interim reanalysis: configuration and performance of the data assimilation system, Q. J. Roy. Meteor. Soc., 137, 553-597, 2011.

Diner, D. J., Beckert, J. C., Reilly, T. H., Bruegge, C. J., Conel, J. E., Kahn, R. A., Martonchik, J. V., Ackerman, T. P., Davies, R., Gerstl, S. A. W., Gordon, H. R., Muller, J. P., Myneni, R. B., Sellers, P. J., Pinty, B., and Verstraete, M. M.: Multi-angle Imaging SpectroRadiometer (MISR) - Instrument description and experiment overview, IEEE T. Geosci. Remote, 36, 1072-1087, 1998.

Douglas, E. M., Beltran-Przekurat, A., Niyogi, D., Pielke, R. A., and Vorosmarty, C. J.: The impact of agricultural intensification and irrigation on land-atmosphere interactions and Indian monsoon precipitation - A mesoscale modeling perspective, Global Planet. Change, 67, 117-128, 2009. 
Easter, R. C., Ghan, S. J., Zhang, Y., Saylor, R. D., Chapman, E. G., Laulainen, N. S., Abdul-Razzak, H., Leung, L. R., Bian, X. D., and Zaveri, R. A.: MIRAGE: Model description and evaluation of aerosols and trace gases, J. Geophys. Res.-Atmos., 109, D20210, doi:10.1029/2004jd004571, 2004.

Fast, J. D., Gustafson, W. I., Easter, R. C., Zaveri, R. A., Barnard, J. C., Chapman, E. G., Grell, G. A., and Peckham, S. E.: Evolution of ozone, particulates, and aerosol direct radiative forcing in the vicinity of Houston using a fully coupled meteorology-chemistry-aerosol model, J. Geophys. Res.-Atmos., 111, D21305, doi:10.1029/2005jd006721, 2006.

Ghan, S., Laulainen, N., Easter, R., Wagener, R., Nemesure, S., Chapman, E., Zhang, Y., and Leung, R.: Evaluation of aerosol direct radiative forcing in MIRAGE, J. Geophys. Res.-Atmos., 106, 5295-5316, 2001.

Ginoux, P., Chin, M., Tegen, I., Prospero, J. M., Holben, B., Dubovik, O., and Lin, S. J.: Sources and distributions of dust aerosols simulated with the GOCART model, J. Geophys. Res.Atmos., 106, 20255-20273, 2001.

Grell, G. A. and Devenyi, D.: A generalized approach to parameterizing convection combining ensemble and data assimilation techniques, Geophys. Res. Lett., 29, 38-1-38-4, doi:10.1029/2002g1015311, 2002.

Grell, G. A., Peckham, S. E., Schmitz, R., McKeen, S. A., Frost, G., Skamarock, W. C., and Eder, B.: Fully coupled "online" chemistry within the WRF model, Atmos. Environ., 39, 6957-6975, 2005.

Guenther, A. B., Jiang, X., Heald, C. L., Sakulyanontvittaya, T., Duhl, T., Emmons, L. K., and Wang, X.: The Model of Emissions of Gases and Aerosols from Nature version 2.1 (MEGAN2.1): an extended and updated framework for modeling biogenic emissions, Geosci. Model Dev., 5, 1471-1492, doi:10.5194/gmd-51471-2012, 2012.

Guimberteau, M., Laval, K., Perrier, A., and Polcher, J.: Global effect of irrigation and its impact on the onset of the Indian summer monsoon, Clim. Dynam., 39, 1329-1348, 2012.

Hong, S. Y., Noh, Y., and Dudhia, J.: A new vertical diffusion package with an explicit treatment of entrainment processes, Mon. Weather Rev., 134, 2318-2341, 2006.

Hsu, N. C., Gautam, R., Sayer, A. M., Bettenhausen, C., Li, C., Jeong, M. J., Tsay, S.-C., and Holben, B. N.: Global and regional trends of aerosol optical depth over land and ocean using SeaWiFS measurements from 1997 to 2010, Atmos. Chem. Phys., 12, 8037-8053, doi:10.5194/acp-12-8037-2012, 2012.

Hsu, N. C., Tsay, S. C., King, M. D., and Herman, J. R.: Aerosol properties over bright-reflecting source regions, IEEE T. Geosci. Remote, 42, 557-569, 2004.

Huang, J., Fu, Q., Su, J., Tang, Q., Minnis, P., Hu, Y., Yi, Y., and Zhao, Q.: Taklamakan dust aerosol radiative heating derived from CALIPSO observations using the Fu-Liou radiation model with CERES constraints, Atmos. Chem. Phys., 9, 4011-4021, doi:10.5194/acp-9-4011-2009, 2009.

Huffman, G. J., Adler, R. F., Morrissey, M. M., Bolvin, D. T., Curtis, S., Joyce, R., McGavock, B., and Susskind, J.: Global precipitation at one-degree daily resolution from multisatellite observations, J. Hydrometeorol., 2, 36-50, 2001.

Huffman, G. J., Adler, R. F., Bolvin, D. T., Gu, G. J., Nelkin, E. J., Bowman, K. P., Hong, Y., Stocker, E. F., and Wolff, D. B.: The TRMM multisatellite precipitation analysis (TMPA): Quasi- global, multiyear, combined-sensor precipitation estimates at fine scales, J. Hydrometeorol., 8, 38-55, 2007.

Iacono, M. J., Delamere, J. S., Mlawer, E. J., Shephard, M. W., Clough, S. A., and Collins, W. D.: Radiative forcing by long-lived greenhouse gases: Calculations with the AER radiative transfer models, J. Geophys. Res.-Atmos., 113, D13103, doi:10.1029/2008jd009944, 2008.

Jin, Q. J., Wei, J. F., and Yang, Z. L.: Positive response of Indian summer rainfall to Middle East dust, Geophys. Res. Lett., 41, 4068-4074, 2014.

Kuhlmann, J. and Quaas, J.: How can aerosols affect the Asian summer monsoon? Assessment during three consecutive premonsoon seasons from CALIPSO satellite data, Atmos. Chem. Phys., 10, 4673-4688, doi:10.5194/acp-10-4673-2010, 2010.

Kulmala, M., Toivonen, A., Makela, J. M., and Laaksonen, A.: Analysis of the growth of nucleation mode particles observed in Boreal forest, Tellus B, 50, 449-462, 1998.

Lau, K. M. and Kim, K. M.: Comment on '“Elevated heat pump' hypothesis for the aerosol-monsoon hydroclimate link: 'Grounded' in observations?" by S. Nigam and M. Bollasina, J. Geophys. Res.-Atmos., 116, D07203, doi:10.1029/2010jd014800, 2011.

Lau, K. M., Kim, M. K., and Kim, K. M.: Asian summer monsoon anomalies induced by aerosol direct forcing: the role of the Tibetan Plateau, Clim. Dynam., 26, 855-864, 2006.

Levine, R. C. and Turner, A. G.: Dependence of Indian monsoon rainfall on moisture fluxes across the Arabian Sea and the impact of coupled model sea surface temperature biases, Clim. Dynam., 38, 2167-2190, 2012.

Lim, K. S. S., Fan, J. W., Leung, R., Ma, P. L., Singh, B., Zhao, C., Zhang, Y., Zhang, G., and Song, X. L.: Investigation of aerosol indirect effects using a cumulus microphysics parameterization in a regional climate model, J. Geophys. Res.-Atmos., 119, 906926, 2014.

Lin, Y. L., Farley, R. D., and Orville, H. D.: Bulk Parameterization of the Snow Field in a Cloud Model, J. Clim. Appl. Meteorol., 22, 1065-1092, 1983.

Liu, X., Easter, R. C., Ghan, S. J., Zaveri, R., Rasch, P., Shi, X., Lamarque, J.-F., Gettelman, A., Morrison, H., Vitt, F., Conley, A., Park, S., Neale, R., Hannay, C., Ekman, A. M. L., Hess, P., Mahowald, N., Collins, W., Iacono, M. J., Bretherton, C. S., Flanner, M. G., and Mitchell, D.: Toward a minimal representation of aerosols in climate models: description and evaluation in the Community Atmosphere Model CAM5, Geosci. Model Dev., 5, 709-739, doi:10.5194/gmd-5-709-2012, 2012.

Mahowald, N., Albani, S., Kok, J. F., Engelstaeder, S., Scanza, R., Ward, D. S., and Flanner, M. G.: The size distribution of desert dust aerosols and its impact on the Earth system, Aeolian Res., 15, 53-71, 2014.

McFiggans, G., Artaxo, P., Baltensperger, U., Coe, H., Facchini, M. C., Feingold, G., Fuzzi, S., Gysel, M., Laaksonen, A., Lohmann, U., Mentel, T. F., Murphy, D. M., O’Dowd, C. D., Snider, J. R., and Weingartner, E.: The effect of physical and chemical aerosol properties on warm cloud droplet activation, Atmos. Chem. Phys., 6, 2593-2649, doi:10.5194/acp-6-2593-2006, 2006.

Middleton, P., Stockwell, W. R., and Carter, W. P. L.: Aggregation and Analysis of Volatile Organic-Compound Emissions for Regional Modeling, Atmos. Environ. A-Gen., 24, 1107-1133, 1990. 
Moron, V. and Robertson, A. W.: Interannual variability of Indian summer monsoon rainfall onset date at local scale, Int. J. Climatol., 34, 1050-1061, 2014.

Myhre, G., Stordal, F., Johnsrud, M., Kaufman, Y. J., Rosenfeld, D., Storelvmo, T., Kristjansson, J. E., Berntsen, T. K., Myhre, A., and Isaksen, I. S. A.: Aerosol-cloud interaction inferred from MODIS satellite data and global aerosol models, Atmos. Chem. Phys., 7, 3081-3101, doi:10.5194/acp-7-3081-2007, 2007.

Nigam, S. and Bollasina, M.: "Elevated heat pump" hypothesis for the aerosol-monsoon hydroclimate link: "Grounded" in observations?, J. Geophys. Res.-Atmos., 115, D16201, doi:10.1029/2009jd013800, 2010.

Peters, K. and Eiden, R.: Modeling the Dry Deposition Velocity of Aerosol-Particles to a Spruce Forest, Atmos. Environ. A-Gen., 26, 2555-2564, 1992.

Prive, N. C. and Plumb, R. A.: Monsoon dynamics with interactive forcing. Part I: Axisymmetric studies, J. Atmos. Sci., 64, 14171430, 2007a.

Prive, N. C. and Plumb, R. A.: Monsoon dynamics with interactive forcing. Part II: Impact of eddies and asymmetric geometries, J. Atmos. Sci., 64, 1431-1442, 2007b.

Prospero, J. M., Ginoux, P., Torres, O., Nicholson, S. E., and Gill, T. E.: Environmental characterization of global sources of atmospheric soil dust identified with the Nimbus 7 Total Ozone Mapping Spectrometer (TOMS) absorbing aerosol product, Rev. Geophys., 40, 1002, doi:10.1029/2000rg000095, 2002.

Ramanathan, V., Chung, C., Kim, D., Bettge, T., Buja, L., Kiehl, J. T., Washington, W. M., Fu, Q., Sikka, D. R., and Wild, M.: Atmospheric brown clouds: Impacts on South Asian climate and hydrological cycle, P. Natl. Acad. Sci. USA, 102, 5326-5333, 2005.

Rienecker, M. M., Suarez, M. J., Gelaro, R., Todling, R., Bacmeister, J., Liu, E., Bosilovich, M. G., Schubert, S. D., Takacs, L., Kim, G. K., Bloom, S., Chen, J. Y., Collins, D., Conaty, A., Da Silva, A., Gu, W., Joiner, J., Koster, R. D., Lucchesi, R., Molod, A., Owens, T., Pawson, S., Pegion, P., Redder, C. R., Reichle, R., Robertson, F. R., Ruddick, A. G., Sienkiewicz, M., and Woollen, J.: MERRA: NASA's Modern-Era Retrospective Analysis for Research and Applications, J. Climate, 24, 3624-3648, 2011.

Ruijgrok, W., Davidson, C. I., and Nicholson, K. W.: Dry Deposition of Particles - Implications and Recommendations for Mapping of Deposition over Europe, Tellus B, 47, 587-601, 1995.

Schell, B., Ackermann, I. J., Hass, H., Binkowski, F. S., and Ebel, A.: Modeling the formation of secondary organic aerosol within a comprehensive air quality model system, J. Geophys. Res.Atmos., 106, 28275-28293, 2001.

Shin, H. H. and Hong, S. Y.: Intercomparison of Planetary Boundary-Layer Parametrizations in the WRF Model for a Single Day from CASES-99, Bound.-Lay. Meteorol., 139, 261-281, 2011.

Skamarock, W. C., Klemp, J. B., Dudhia, J., Gill, D. O., Barker, D. M., Duda, M. G., Huang, X.-Y., Wang, W., and Powers, J. G.: A Description of the Advanced Research WRF Version3, NCAR TECHNICAL NOTE, available at: http://www2.mmm.ucar.edu/ wrf/users/docs/arw_v3.pdf (last access: 9 June 2015), 2008.
Solmon, F., Nair, V. S., and Mallet, M.: Increasing Arabian dust activity and the Indian summer monsoon, Atmos. Chem. Phys., 15, 8051-8064, doi:10.5194/acp-15-8051-2015, 2015.

Stockwell, W. R., Kirchner, F., Kuhn, M., and Seefeld, S.: A new mechanism for regional atmospheric chemistry modeling, J. Geophys. Res.-Atmos., 102, 25847-25879, 1997.

Trenberth, K. E.: Atmospheric moisture recycling: Role of advection and local evaporation, J. Climate, 12, 1368-1381, 1999.

Utry, N., Ajtai, T., Pintér, M., Tombácz, E., Illés, E., Bozóki, Z., and Szabó, G.: Mass-specific optical absorption coefficients and imaginary part of the complex refractive indices of mineral dust components measured by a multi-wavelength photoacoustic spectrometer, Atmos. Meas. Tech., 8, 401-410, doi:10.5194/amt8-401-2015, 2015.

Vinoj, V., Rasch, P. J., Wang, H. L., Yoon, J. H., Ma, P. L., Landu, K., and Singh, B.: Short-term modulation of Indian summer monsoon rainfall by West Asian dust, Nat. Geosci., 7, 308-313, 2014.

Wagner, R., Ajtai, T., Kandler, K., Lieke, K., Linke, C., Müller, T., Schnaiter, M., and Vragel, M.: Complex refractive indices of Saharan dust samples at visible and near UV wavelengths: a laboratory study, Atmos. Chem. Phys., 12, 2491-2512, doi:10.5194/acp-12-2491-2012, 2012.

Wang, C., Jeong, G. R., and Mahowald, N.: Particulate absorption of solar radiation: anthropogenic aerosols vs. dust, Atmos. Chem. Phys., 9, 3935-3945, doi:10.5194/acp-9-3935-2009, 2009a.

Wang, C., Kim, D., Ekman, A. M. L., Barth, M. C., and Rasch, P. J.: Impact of anthropogenic aerosols on Indian summer monsoon, Geophys. Res. Lett., 36, L21704, doi:10.1029/2009g1040114, 2009b.

Wei, J., Su, H., and Yang, Z.-L.: Impact of moisture flux convergence and soil moisture on precipitation: a case study for the southern United States with implications for the globe, Clim. Dynam., doi:10.1007/s00382-015-2593-2, 2015.

Wesely, M. L.: Parameterization of Surface Resistances to Gaseous Dry Deposition in Regional-Scale Numerical-Models, Atmos. Environ., 23, 1293-1304, 1989.

Whitby, E. R. and McMurry, P. H.: Modal aerosol dynamics modeling, Aerosol Sci. Tech., 27, 673-688, 1997.

Xie, P. P. and Arkin, P. A.: Global precipitation: A 17-year monthly analysis based on gauge observations, satellite estimates, and numerical model outputs, B. Am. Meteorol. Soc., 78, 2539-2558, 1997.

Zender, C. S., Bian, H. S., and Newman, D.: Mineral Dust Entrainment and Deposition (DEAD) model: Description and 1990s dust climatology, J. Geophys. Res.-Atmos., 108, 4416, doi:10.1029/2002jd002775, 2003a.

Zender, C. S., Newman, D., and Torres, O.: Spatial heterogeneity in aeolian erodibility: Uniform, topographic, geomorphic, and hydrologic hypotheses, J. Geophys. Res.-Atmos., 108, 4543, doi:10.1029/2002jd003039, 2003b.

Zhang, L. M., Gong, S. L., Padro, J., and Barrie, L.: A sizesegregated particle dry deposition scheme for an atmospheric aerosol module, Atmos. Environ., 35, 549-560, 2001. 